\title{
Evaluation of a Newly Designed Immunochromatographic Test using Gold Nanoparticles and Recombinant Antigen gra7 for Rapid Diagnosis of Human Toxoplasmosis
}

\author{
Hassan Morovati Khamsi ${ }^{1}$, Seyyed javad SeyyedTabaei ${ }^{2}$, Mehrdad Gholamzad ${ }^{3}$ *
}

1. Department of Quality Control, Razi Vaccine and Serum Research Institute, Agricultural Research, Education and Extension Organization (AREEO), Karaj, Iran

2. Department of Parasitology and Mycology, Faculty of Medicine, Shahid Beheshti University of Medical Sciences, Tehran, Iran

3. Department of Microbiology and Immunology, Faculty of Medicine, Tehran Medical Sciences, Islamic Azad University, Tehran, Iran

ABSTRACT

Background: One of the most important complications of toxoplasmosis is its early diagnosis. It seems that GRA7 protein can be a good candidate for detection of the acute phase in Toxoplasmosis. Accordingly, the present study aimed to diagnose toxoplasmosis via a newly immunochromatographic test using recombinant antigen gra7.

Methods: The parasite was cultured in mice and then were used for DNA extraction. The gra7 gene was amplified by PCR and cloned into the pET-32a (+) plasmid. Thereafter, the recombinant vector was transferred into the Escherichia coli Rosetta strain and gra7 was detected via SDS-PAGE and western blotting. The bacterial lysate was used to purify the protein by $\mathrm{Ni}$ NTA affinity chromatography. Anti-human gold conjugated antibody, test line and control line were injected to conjugate pad and nitrocellulose membrane, respectively, and all the layer were assembled. By using serum of patients and healthy individuals, manufactured kits were evaluated.

Results: Our results indicated that the selected gene was correctly cloned and the protein of interest was produced and purified. The test revealed sensitivity and specificity of 100 and 96.7 percent, respectively. The kit was also shown to be stable over 16 weeks in $37^{\circ} \mathrm{C}$

Conclusion: The choice of antigen based on cellular and clinical features of the parasite, as well as the use of previous outcomes yielded to develop a rapid diagnostic test for toxoplasmosis.

Keywords: Toxoplasmosis, Immunochromatoga, gra7 antigen, RPD, Gold nanoparticles

Received: 2019/11/27; $\quad$ Accepted: 2019/12/09; Published Online: 2020/01/01

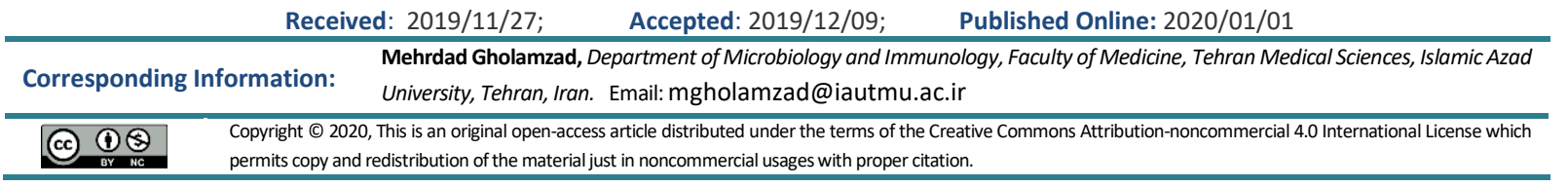

Use your device to scan and read the article online

Morovati Khamsi H, SeyyedTabaei SJ, Gholamzad M. Evaluation of a Newly Designed Immunochromatographic Test using Gold Nanoparticles and Recombinant Antigen gra7 for Rapid Diagnosis of Human Toxoplasmosis. Iran J Med Microbiol. 2020; 14 (1):101-115

Download citation: BibTeX | RIS | EndNote | Medlars | ProCite | Reference Manager | RefWorks

Send citation to: $\otimes_{\text {Mendeley }} \mathbf{z}$ zotero $\mathbb{E}$ RefWorks 


\section{Introduction}

Toxoplasma gondii is a mandatory intracellular parasite that causes toxoplasmosis. About 500 million to one billion people in the world are infected with the parasite, which is mainly caused by eating undercooked meat, fruits, vegetables, or being exposed to soil and water contaminated with the parasite's infected eggs. (1). Manifestations of the disease range from mild flulike symptoms to lymphadenopathy and Chorioretinitis. Transmission of a primary (acute) infection from a pregnant mother to the fetus is largely asymptomatic and can lead to miscarriage or congenital abnormalities such as hydrocephalus, microcephaly, intracranial calcification, Chorioretinitis, blindness, epilepsy, mental retardation, or problems in motor abilities (2). On the other hand, the activation of a chronic infection in the nervous system following a weakened or impaired immune system in people with AIDS, organ transplants, or in patients with lymphoproliferative diseases can lead to central nervous system damage or complications such as encephalitis for which lack of in time diagnosis and proper treatment can have deadly consequences (3). Early detection of acute and chronic toxoplasmosis, followed by appropriate drug treatment in at-risk individuals, can reduce the severity of symptoms and the occurrence of life-threatening injuries (4). Therefore, the aim of this study was to use recombinant gra7 protein to design immunochromatographic methods for rapid diagnosis of specific IgG against $T$. gondii in three minutes.

\section{Materials and Methods}

\section{Toxoplasma Culture and DNA Extraction}

This experimental study was performed in 2017 with 204 serum samples from different laboratories in Tehran using non-probable sampling method. Toxoplasmainduced $\mathrm{RH}$ angles were used in frozen form from the Quality Control Department of the Razi Vaccine and Serum Research Institute. To remove the preservative, the parasite was washed once with PBS solution and then cultured twice by successive intracranial passages in the mouse. For the reproduction and maintenance of the parasite, $0.5 \mathrm{~mL}$ of peritoneal fluid containing $2 \times 10^{5}$ live parasites was injected into each mouse and $100 \mu \mathrm{L} / \mathrm{mL}$ of penicillin was injected intraperitoneally. After 3 to 4 days, the peritoneal cavity of infected mouse was washed with $5 \mathrm{~mL}$ of cold PBS buffer, and the tacos were collected and stored at $-20^{\circ} \mathrm{C}$. To extract the genomic DNA, the toxoid plasma toxins were extracted from the DNA extraction kit by Synagen (Iran) in the DNG method according to the manufacturer's instructions.

\section{Primer Design for GRA7 Gene and PCR}

The gra7 gene sequence was extracted from the NCBI gene bank and designed with the enzyme sites of BgllI and Xhol. The sequence of primers was confirmed using Gene Runner software.

\section{GRA7 Forward: CAGCCCAGATCTGATGGCACGACACGCAAT}

\section{GRA7 Reverse: GTGGTGCTCGAGTTACTGGCGGGCATCCTC}

The gra7 gene was amplified using PCR. The gra7 gene proliferation timing program using PCR includes initial denaturation for 5 minutes and $96^{\circ} \mathrm{C}$, secondary denaturation for 30 seconds and $95^{\circ} \mathrm{C}$ temperature, Annealing for 30 seconds and $58^{\circ} \mathrm{C}$ temperature, Extension for 1 minute and temperature $7 \mathrm{C} 72$ and final extension for 10 minutes at $72^{\circ} \mathrm{C}$. In this process, $0.4 \mu \mathrm{M}$ of each primer, $200 \mu \mathrm{m}$ of any dNTP type, 1.5 unit / mL of Taq polymerase enzyme, $5 \mu \mathrm{L}$ PCR buffer containing MgSO4 and $200 \mathrm{ng}$ of the sample DNA with a final volume of $50 \mu \mathrm{L}$ were used.

\section{Preparation of Recombinant Plasmid and Cloning}

The plasmid pET-32a (+) vector was first cut using BgllI and Xhol and added to the purified PCR product. By adding the enzyme T4 ligase, the gene was added to the Recombinant Plasmid.

The recombinant plasmid was transferred to the Competent Cell Escherichia coli $\mathrm{DH} 5 \alpha$ by heat shock. The bacterium was cultured in an LB culture medium containing $100 \mu \mathrm{g} / \mathrm{mL}$ of antibiotic. The recombinant plasmid was extracted using double enzyme digestion on gra7 -pET-32a (+) and PCR for the gra7 gene to confirm the accuracy of bacterial transformation.

\section{Expression, Confirmation and Purification of GRA7 Protein}

The multiplied recombinant plasmid was transferred to $E$. coli Rosetta (DE3). A colony was removed from the newly transformed plate and cultured in a tube containing liquid LB and ampicillin, and the next day in a $25 \mathrm{~mL}$ Erlenmeyer flask. Four, six, and eight hours after induction, the environment was sampled. The collected samples were centrifuged at $6000 \mathrm{rpm}$ and the final precipitate was stored in a freezer at $-20^{\circ} \mathrm{C}$. The Western blot method was used to confirm the gene expression. In order to purify gra7 by Ni-NTA method, first the cell sediment was melted at room temperature and the cells were lysed and then the cellular lyses were evaluated directly by SDS-PAGE. Also, the lyses-resin mixture was carefully passed through the Ni-NTA chromatography column and its output was collected.

\section{Blotting Test}

At this stage, the antigen gra7 was cut on the nitrocellulose paper and after the blocking phase with bovine serum albumin, the serum of patients with toxoplasmosis was evaluated with 1:30 dilutions. In this study, 204 serums from different laboratories that were examined and collected by CLIA method were used. There 
were 30 serums for people with clinical symptoms, 70 serums with IgM antibodies to Toxoplasma, 74 serums with IgG antibodies against Toxoplasma and 30 negative serums (no IgG antibodies against Toxoplasma). Also, 30 serum samples of people with IgG antibodies against other diseases, all of which were negative for IgM antibodies and IgG antibodies to toxoplasma, were evaluated for Bovine Serum Albumin (BSA). Ventricular leishmaniasis $(n=5)$, Strongyloidiasis $(n=1)$, malaria $(n=13)$, fascioliasis $(n=4)$, hepatitis $(n=3)$, hydatid cyst $(n=4)$ were used.

\section{Immunochromatography Strip}

After preparing the colloidal gold and conjugating the Anti-human IgG according to the relevant protocol (18), the tape was designed and tested. The conjugated solution was poured on the conjugation pad. A recombinant gra7 antigen suspension was added to the test line area. The control line was sampled with antibodies against the mouse antibody. All sheets were cut to a width of $4 \mathrm{~mm}$.

The accelerated method was used to evaluate the kit stability time. The shelf life of the kit was calculated for 24 months.

\section{Results}

After DNA extraction from the parasite, the PCR reaction was performed using specific primers on the gene gra7. The gene proliferation band was 726 base pair (Figure 1).

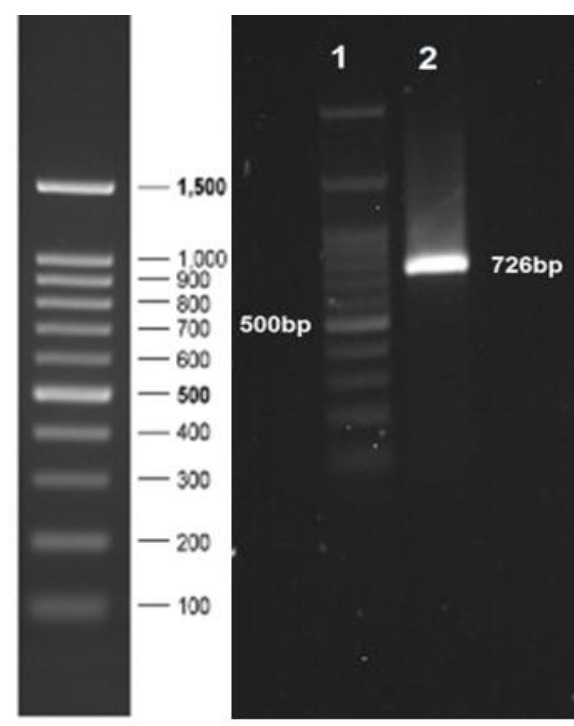

Figure 1. Electrophoresis of gra 7 gene on $1 \%$ agarose gel. Column 1: Marker $100 \mathrm{bp}$, Column 2: Multiplied part of the gra7 gene

The purified PCR product as well as the purified $\mathrm{pET}$ 32a (+) plasmid were cut with Bglll and Xhol cutting enzymes and then connected to each other with the same end, and the recombinant pET-32a (+) -GRA7 plasmid was produced. The recombinant plasmid was then transferred to the bacterium and cultured in the presence of the antibiotic ampicillin. At this stage, the initial recombinant colonies were confirmed by specific primers (Figure $2 \mathrm{a}, \mathrm{b}$ ). a

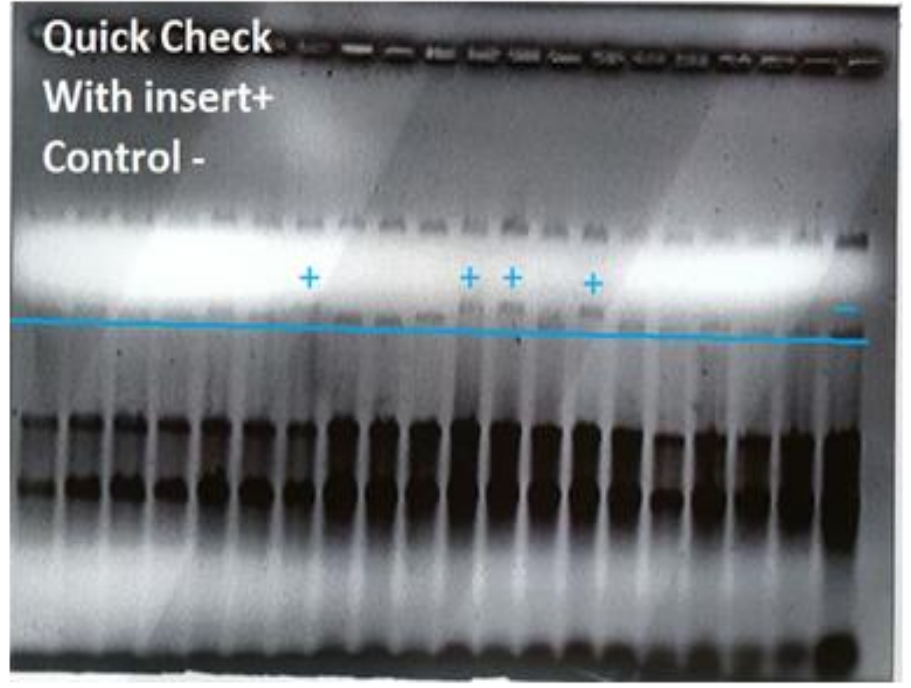

b

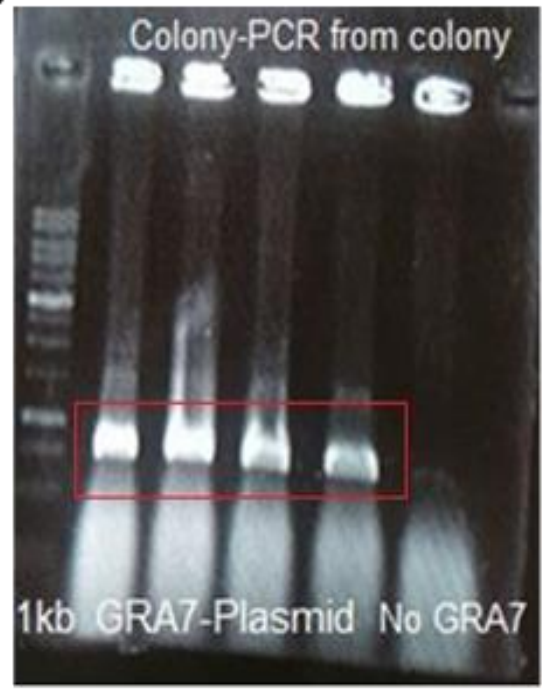

Figure 2. Confirmation of bacterial transformation with recombinant plasmid. a) Quick check test to confirm the presence of recombinant plasmid in bacteria. b) Colony PCR test to confirm gra7 gene in vector.

DNA was extracted from confirmed colonies and finalized by double enzymatic digestion (Figure 3).

Protein expression was induced in IPTG-stimulated bacteria and then confirmed by SDS-PAGE (Figure 4a).
The dot blot test was performed using human serum with IgG antibody against Toxoplasma. 


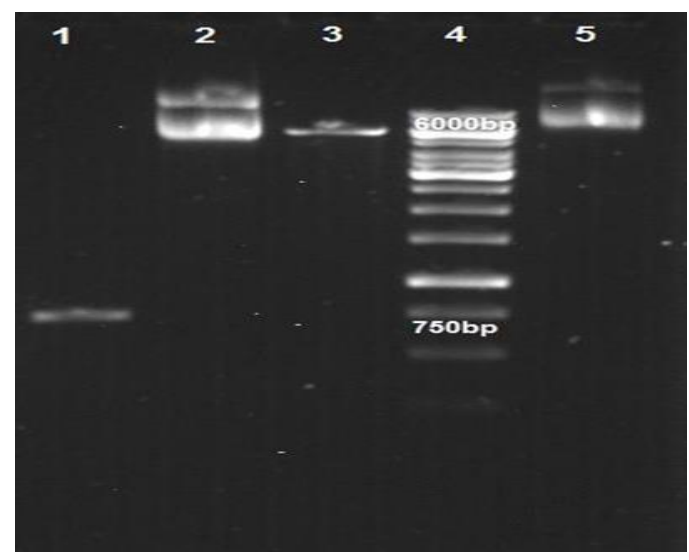

Figure 3. Digestive digestion of pET-32a (+) with Xhol and BgIll enzymes and PCR product of G7 toxin gene. Column 1: gra7 gene, Column 2: Plasmid without gra7, Column 3: Plasmid after enzymatic digestion, Column 4: Molecular size index 1 kbp, Column 5: recombinant plasmid plas-32a (+) - gra7
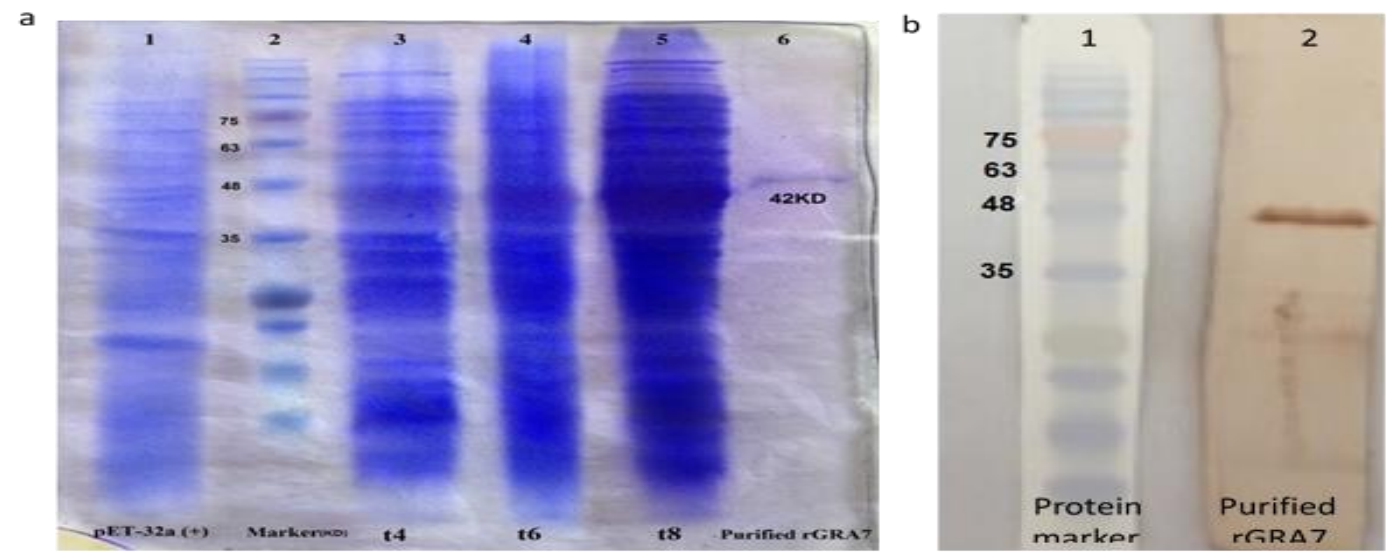

Figure 4. Electrophoresis of lyse bacterial cell with pET-32a (+)-gra7 plasmid and evaluation of recombinant protein expression r gra7 on SDS-PAGE gel. a) Column 1: pET-32a vector (+), column 2: molecular weight index, column 3: pET-32a-gra7

four hours after induction, column 4: pET-32a-gra7 six hours after induction, column 5 : pET-32a-gra7 Eight hours after induction, column 6: recombinant purified protein $r$ gra7. b) Western blot protein gra7 recombinant using conjugated Rabbit anti human IgG. Column 1: Protein marker, Column 2: recombinant GRA7 protein.

\section{Strip Test}

The strip test in the control line section showed a significant red color. However such a significant color was not observed in the test line section with dilutions higher

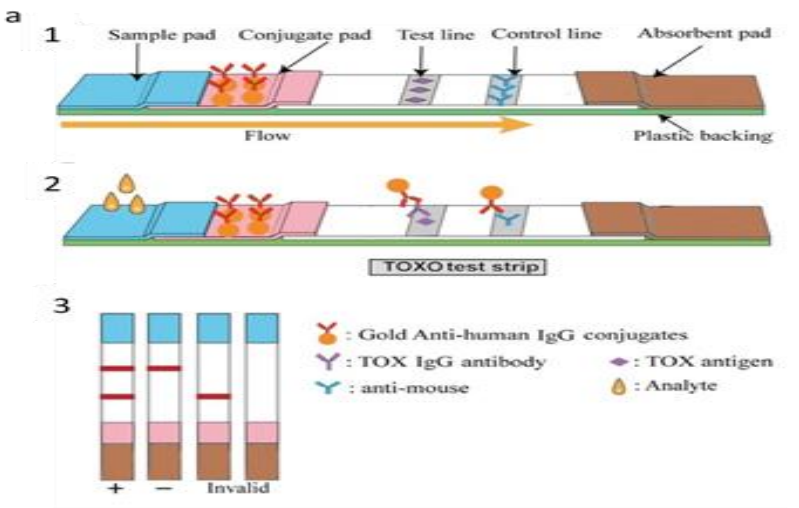

than 1: 8 (Figure b5). Therefore, to perform this test, all serum samples were diluted with a 1: 8 dilution with a buffer. The sensitivity and specificity of the strip test were $100 \%$ and $96.7 \%$, respectively.

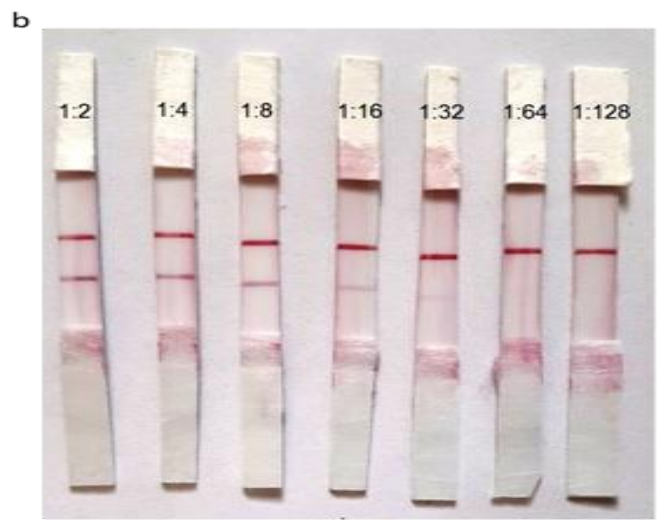

Figure 5. Strip test for rapid detection of Toxoplasma anti-gra7 antibody. a) Schematic image of preparation of strip test components. b) Initial evaluation with the help of positive serum samples with different dilutions 


\section{Stable Kit Strip}

Using the accelerated method, the stabilization time of the kit at $37^{\circ} \mathrm{C}$ was set at 16 months. Using conventional formulas, it is approximately equivalent to 32 months of stability at $4^{\circ} \mathrm{C}$.

\section{Discussion}

Most diagnostic tests used are immunological methods of antibody tracking, each of which has its drawbacks. On the other hand, identifying the specific antigen of the acute phase of the disease is a key step in designing diagnostic methods. Some studies have used the potential of GRA7 protein to diagnose with the ELISA test and reported an $80 \%$ sensitivity and $90 \%$ specificity for the test (11). For an accurate, quick and in time diagnosis, the present study, aimed at using gra7 antigen to design a rapid diagnostic test for toxoplasmosis for the first time, by immunocromatography to eliminate the disadvantages of conventional identification methods as much as possible.

Another group of researchers used SAG2 and ROP2 recombinant antigens to diagnose gonadal toxoplasmosis infection. The suggestion of using the above-mentioned recombinant antigens to make vaccines was emphasized (28). The French researchers also designed the $\lg$ and IgM toxoplasma antibody detection strip in patients' serum and compared it with Abbott's CLIA Automatic Architect method, and the sensitivity and specificity were $97 \%$ and 96\%, respectively. Another group of researchers designed a dedicated IgG strip test against toxoplasma using a recombinant SAG1 antigen that could replace the ELISA method with natural antigens. This number test helped to identify acute phase patients, and therefore suggested that it be used alongside ELISA for further study at the national level (31).

In 2019, another study aimed to develop a simple, portable, and rapid method for detecting toxoplasmosis serum based on the recombinant protein of $T$. gondii SAG1 (rSAG1) and GRA7 (rGRA7). It was found that IgM rGRA7-Dot-ELISA sensitivity and specificity were $87.5 \%$ and $91.1 \%$, respectively (32).

In 2020, a study was performed in Japan to diagnose immunocompromised Gondi antibodies in cats by immunochromatographic imaging based on gra7 antigen. The results of this study showed that TgGRA7ICT is a reliable test for anti-T diagnosis (33).

Using a test designed by the French company LDBIO, a group of American scientists tested the IgG and IgM antibodies in serum by simply examining them with $100 \%$ sensitivity and specificity.

In this study, for the first time, a strip test was designed using a recombinant gra7 antigen to diagnose toxoplasmosis.

This study, by selecting the appropriate antigen based on the important cellular and clinical characteristics of the parasite and using the results of previous tests, led to the successful development and evaluation of the rapid diagnosis of toxoplasmosis. Therefore, the results of this study can reduce the detection time by providing a quick screening solution for people suspected of having toxoplasmosis and also make it easier for a wide range of people to interpret the test results.

\section{Conclusion}

In this study, selecting the appropriate antigen based on the important cellular and clinical characteristics of the parasite along with the use of the results of previous tests led to the successful construction and evaluation of the rapid diagnosis of toxoplasmosis. Therefore, the results of this study can reduce the detection time by providing a quick screening solution for people suspected of having toxoplasmosis and also make it easier for a wide range of people to interpret the test results.

\section{Acknowledgment}

This work has been supported by Shahid Beheshti University of Medical Sciences with the number 265. The authors thank the Vice Chancellor for Research of Shahid Beheshti University of Medical Sciences.

\section{Conflict of Interest}

Authors declared no conflict of interests. 


$$
\begin{aligned}
& \text { مجله ميكروبشناسى يزشكى ايران } \\
& \text { سال If ـ شماره | - بهمن و اسفند } 91 \text { || }
\end{aligned}
$$

\title{
ارزيابى تست تشخيص سريع توكسويلاسموز به روش ايمونوكروماتوكرافى با استفاده از

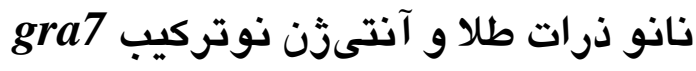

\author{
حسن مروتى خمسى' ، سيد جواد سيد طبايى '، مهرداد غلامزاد"” \\ ا. ا. بخش كنترل كيفى، موسسٔ تحقيقات واكسن و سرمسازى رازى، سازمان تحقيقات، ترويج و آموزش كشاورزى، كرج، ايران

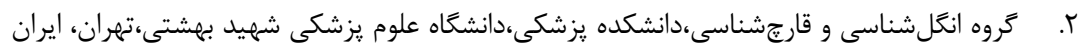

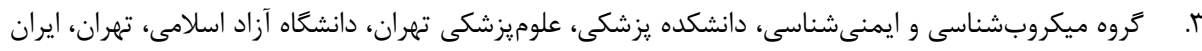

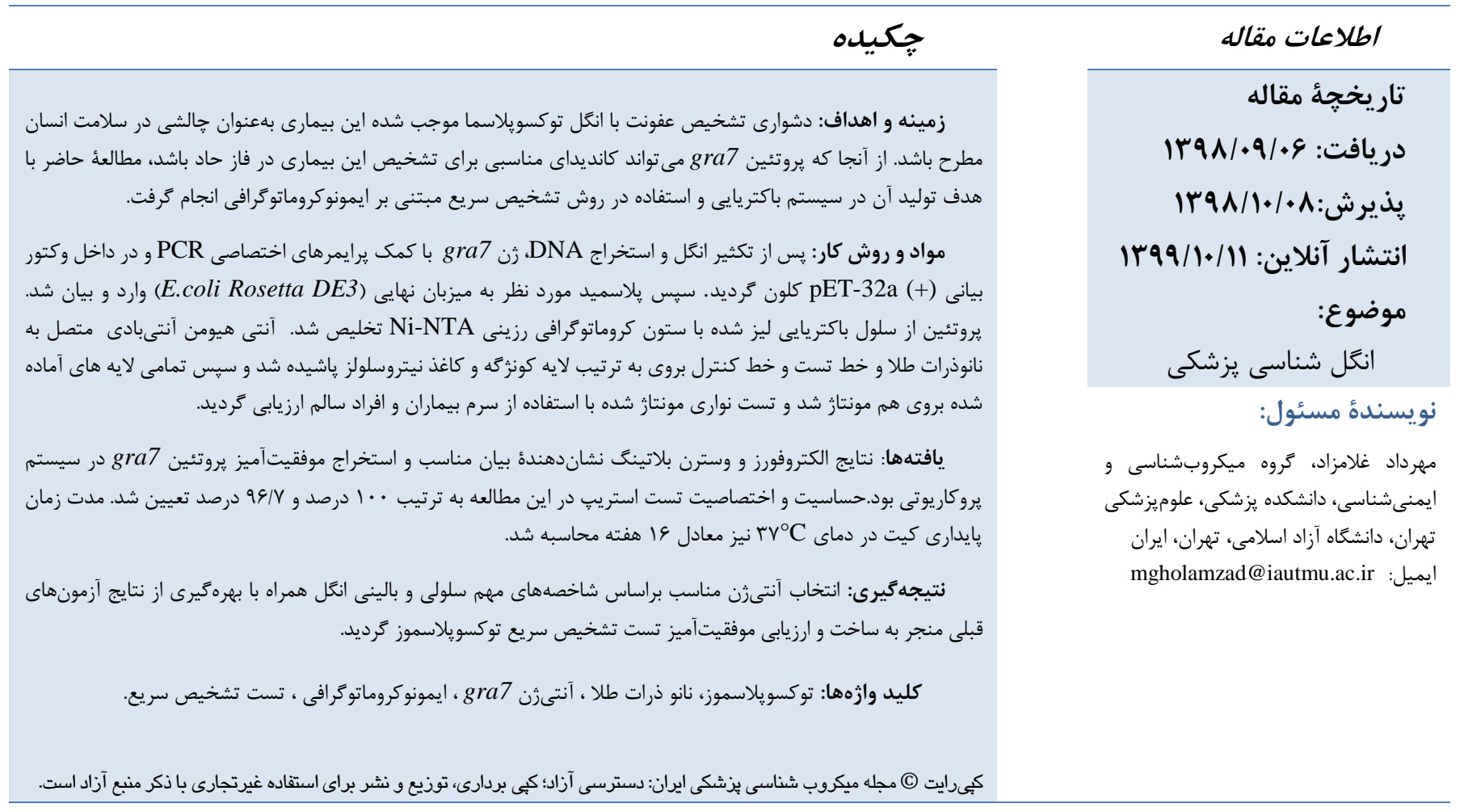

مقلمها

باردار به جنين عمدتا فاقد علائم بوده و مىتواند سقط جنين و يا ناهنجارىهاى مادرزادى مثل هيدروسفالى، ميكروسفالى، كلسيفيه شدن درون مغزى، كوريورتينيت، كورى، صرع، عقبماندگى ذهنى يا حر كتى را به دنبال داشته باشد (؟). از طرفى، فعال شدن عفونت مزمن نهفته در سيستم عصبى به دنبال ضعف يا نقص ايمنى در

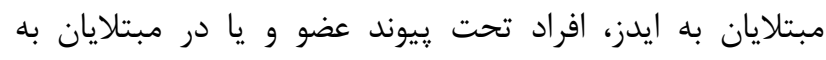
بيمارىهاى lymphoproliferative منجر به آسيب سيستم عصبى لئى مركزى يا عوارضى همانند آنسفاليت مىشود كه در صورت عدم
توكسويلاسما كوندى (Toxoplasma gondii) انگل داخل

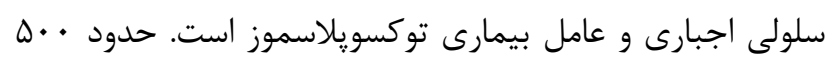
ميليون تا يك ميليارد نفر از جمعيت انسانى در دنيا آلوده به اين انگل تلقى ميىشوند كه عمدتا از طريق خوردن گوشت نيهم يخته، ميوه، سبزيجات و يا در معرض قرارگرفتن با خاك و آب آلوده با لآ تخم (Oocyte) انگل نسبت به آن آلوده شدهاند (1). تظاهرات اين بيمارى طيفى از علائم خفيف شبه آنفولانزا تا لنفودنوياتى و كوريورتينيت را شامل مىشود. انتقال عفونت اوليه (حاد) از مادر 


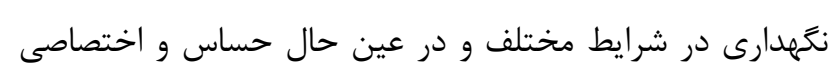
ضرورى بلنظر مى سدس.

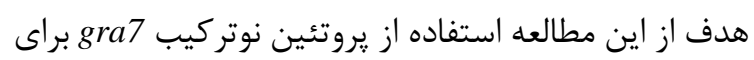

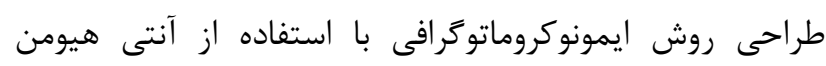
كونزو كه با نانو ذرات طلا براى تشخيص سريع IgG اختصاصى إنى عليه توكسويلاسما گوندى در ب دقيقه است.

\section{روش يزُوهش}

\section{كشت انكَل توكسو يلاسما و استخراج DNA}

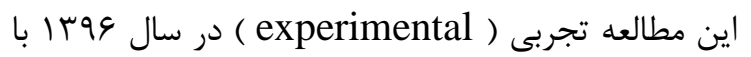

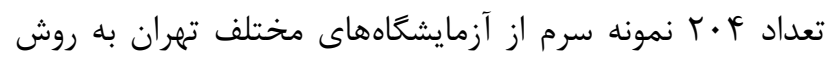

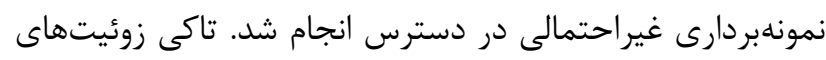

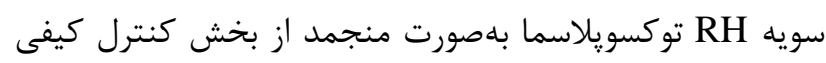

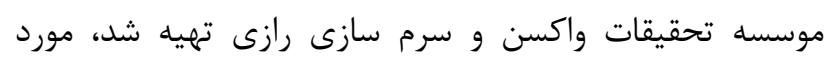

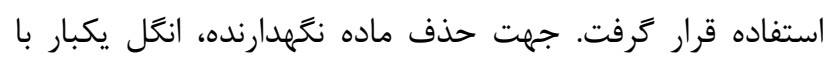

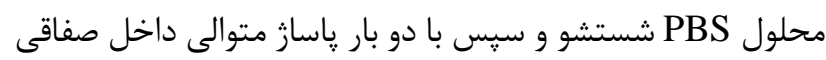

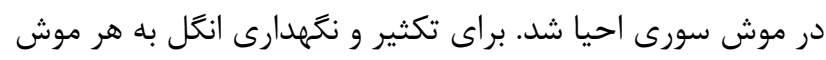

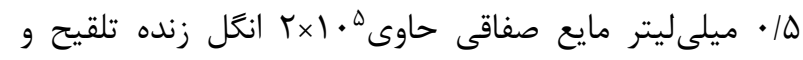
كأرL/mL

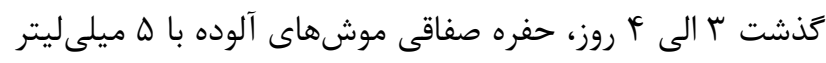

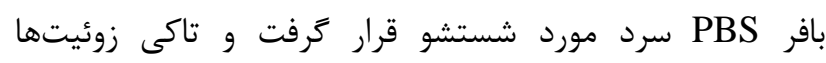
جمعآورى و در • ·- درجه سلسيوس نكَهدارى شدند. در ادامه

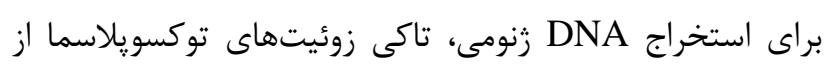

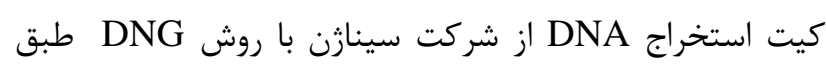

$$
\text { دستور العمل سازنده انجام كرفت. }
$$

\section{طراحى يرايمر براى زن gra7 و انجام PCR}

براى طراحى يرايمر، توالى زن وra7 وان شمارهُ دسترسى

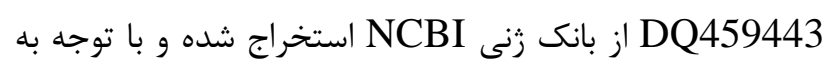

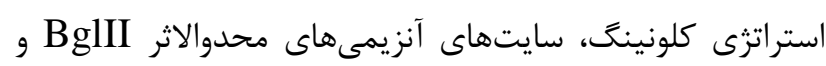
XhoI

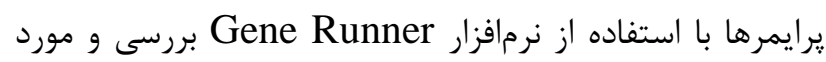

$$
\text { تاييد قرار كرفت. }
$$

gra7 Forward:

CAGCCCAGATCTGATGGCACGACACGCAAT

gra7 Reverse:

GTGGTGCTCGAGTTACTGGCGGGCATCCTC
تشخيص به موقع و درمان مناسب مىتواند نتايج مركَبار به دنبال

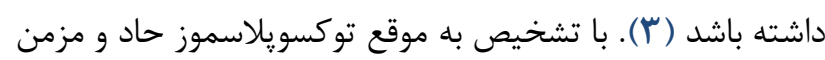

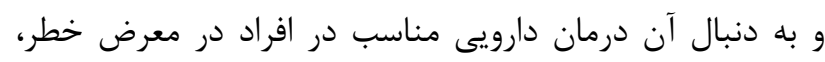

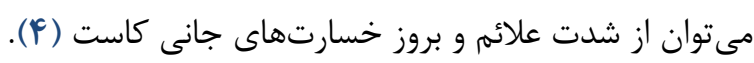

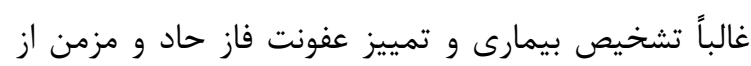

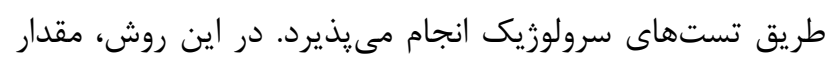

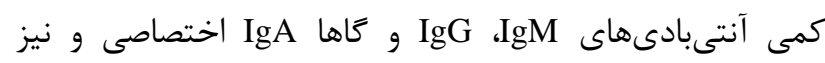
آويديتى IgG (Avidity) عليه توكسويلاسما كوندى اندازهكيرى

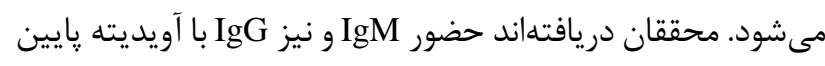

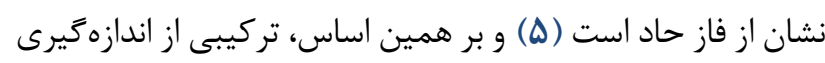

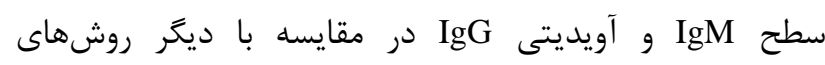

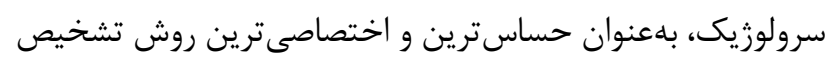

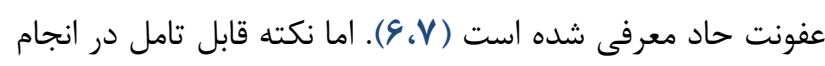

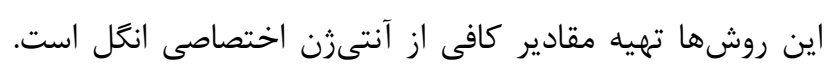

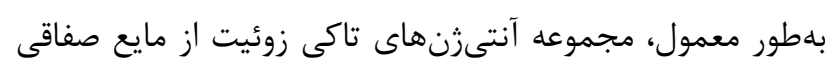

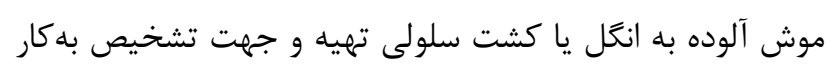

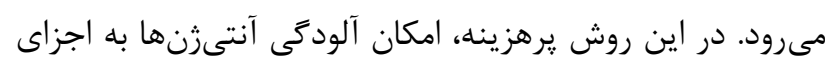

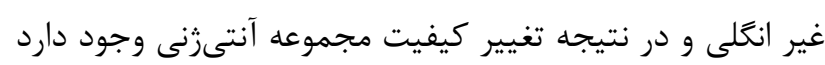

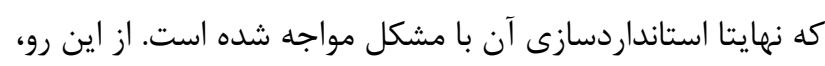

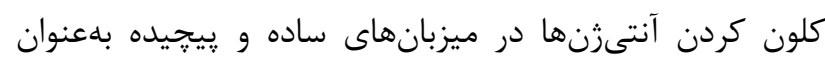
جايخزين بالقوهاى براى روشهاى قديمى توصيه شده است (9، (1).

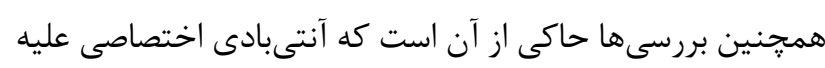

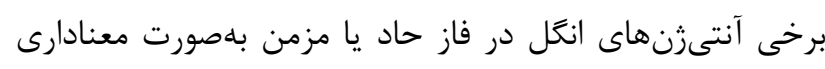

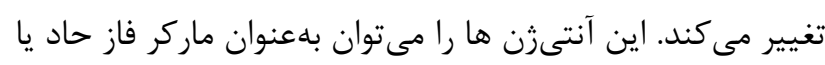

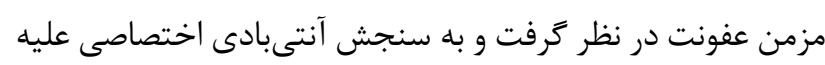

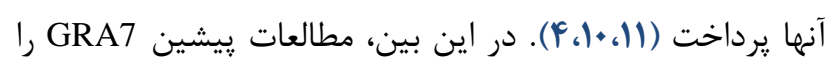

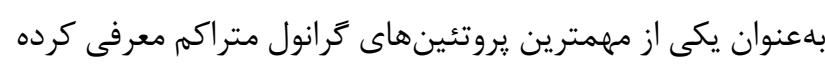

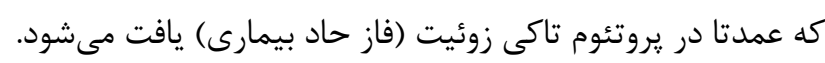

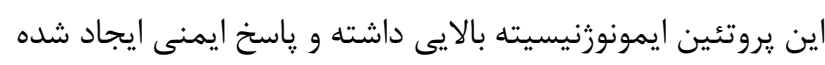

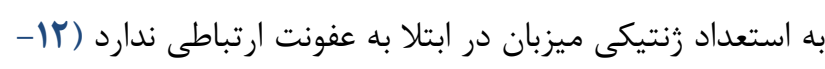

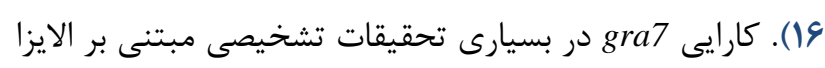

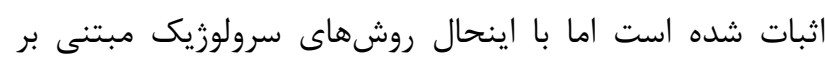
،Enzyme-linked Immunosorbent Assay (ELISA) 9 Immunofluorescence Antibody Test (IFAT) Chemiluminescent Immunoassay (CLIA)

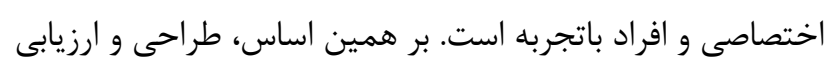

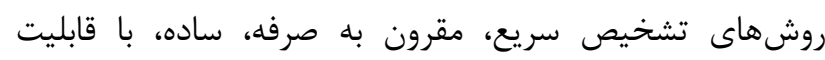


gra7 -pET-32a (Double Digestion) روى (+نزيمى دو كانه بcR و براى زن وra7 صحت ترانسفورماسيون در باكترى تاييد

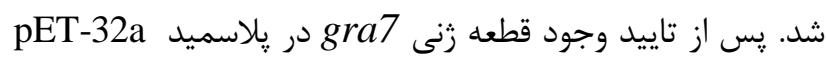
(+) با روشهاى فوقالذكر، براى اطمينان بيشتر بلاسميد نوتركيب

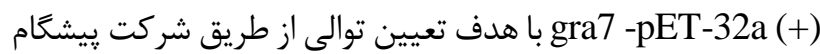

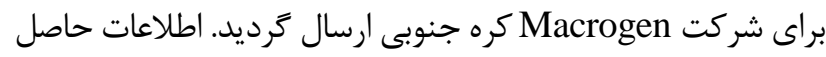

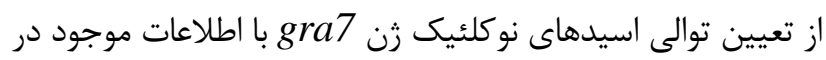
GeneBank

\section{بيان، تاييد و تخليص يروتئين GRA7}

در ادامه يلاسميد نوتركيب تكثير شده به ميزبان بيانى يعنى E.coli Rosetta (DE3) مشابه انتقال يلاسميد به سويه DH5a در مرحله قبل انجام يذيرفت. براى بيان يروتئين نوتركيب GRA7، يك كلنى از يليت تازه

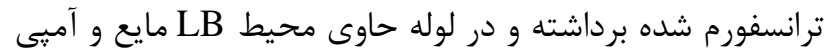

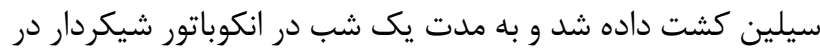

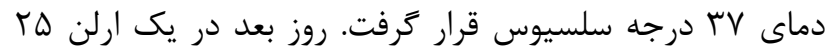

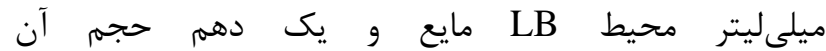
(T/D ميلى ليتر) از كشت شبانه به آن اضافه شد و تحت شرايط

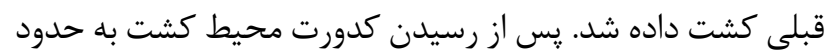

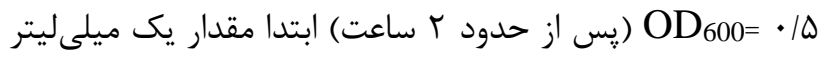

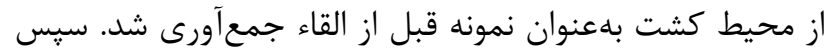
Isopropyl $\beta$ - d-1-thiogalactopyranoside (IPTG)

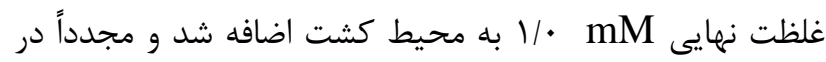

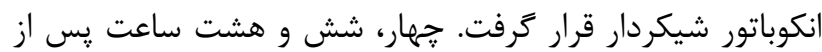
القاء اقدام به نمونه گيرى از محيط شد. نمونههاى جمعآ آورى شده

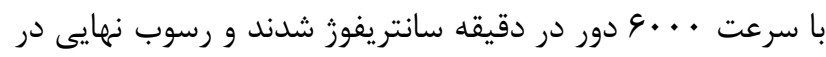

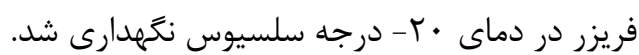
بهمنظور تاييد صحت بيان زن از روش وسترن بلات استفاده

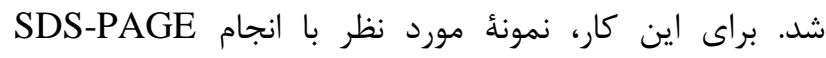

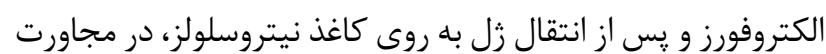

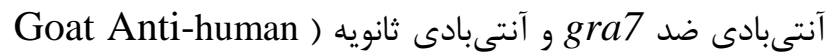
(antibody مورد بررسى قرار كرفت. جهت تخليص gra7 با روش Ni-NTA ابتدا رسوب سلولى در دماى اتاق ذوب شده و براى ليز كردن سلول ها از بافر B فرايند $8 \mathrm{M}$ urea; 0.1 M NaH2PO4; 0.01 M حاوى فيرائرن) Denaturing استفاده شده و سيس ليزات سلولى مستقيما توسط اري (Tris-Cl SDS-PAGE
در نهايت، زن gra7 با استفاده از PCR شامل دناتوراسيون اوليه به مدت له دقيقه و دماى و\ درجه سلسيوس، دناتوراسيون

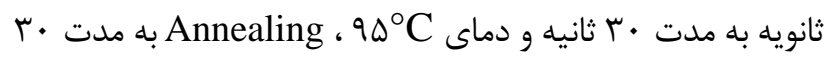

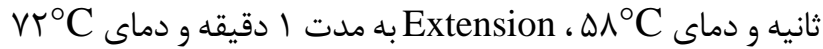
Extension و نهايى به مدت · ا دقيقه و دماى

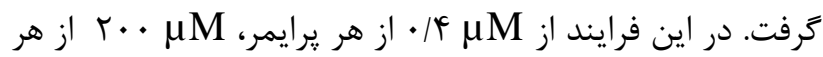

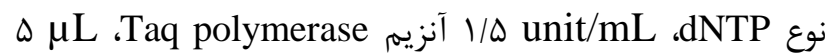
بافر PCR حاوى MgSO4،

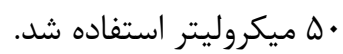

يس از انجام آزمايش، محصول حاصل از PCR با استفاده

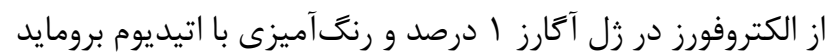

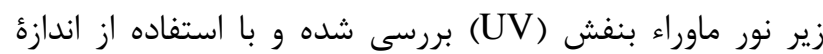

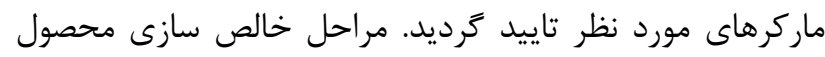

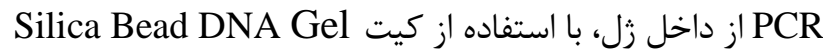
Extraction \# K0513 (Fermentas)

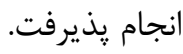

\section{تهيه يلاسميد نوتركيب و كلونسازى}

pET- نوتركيب، يلاسميد بيانى يروكاريوتى DNA جهت ساخت

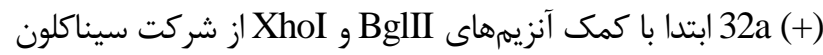
(ايران) بريده شده و به محصول خالص شده PCR اضافه شد. با افزودن

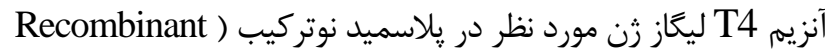

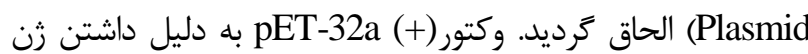

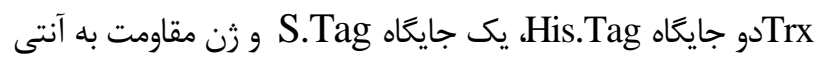
بيوتيك آمبى سيلين بسيار ير كاربرد است و به همين دليل در اين

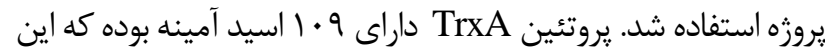

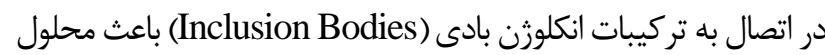

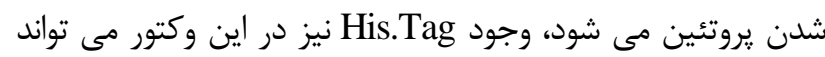
قدرت ما را در شناسايى يروتئين مورد نظر نسبت به ساير حامل ها دو

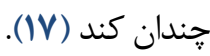

در ادامه براى ترانسفورماسيون باكترى، يلاسميد نوتركيب به

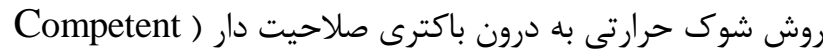

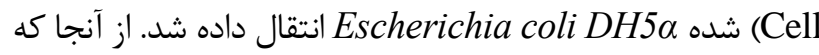

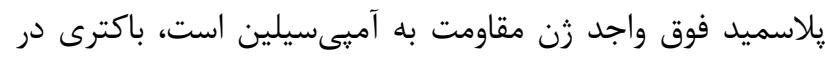

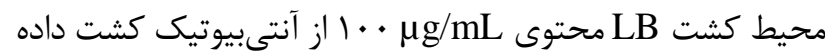
شد. كلنىهاى ظاهر شده در محيط كشت نشانكر حضور باكترى

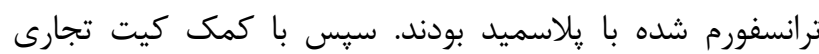

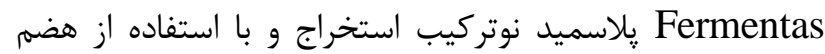




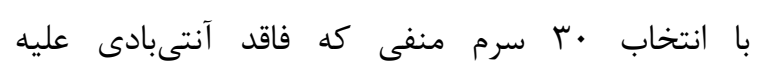

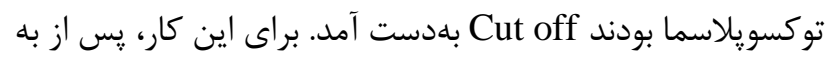

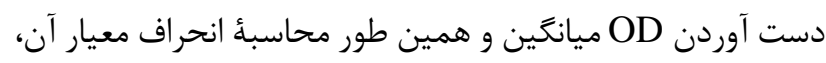

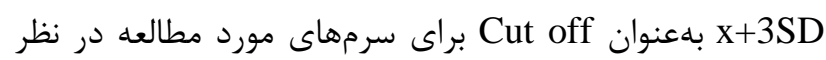
كرفته شد.

\section{استر يب ايمونوكروماتوكر افى}

Anti-human بعد از تهيه طلاى كلوئيدى و كونزو گه كردن

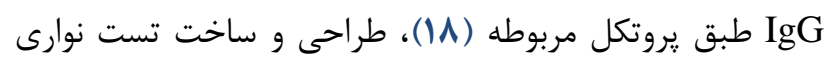

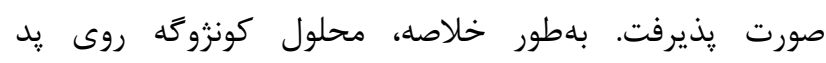

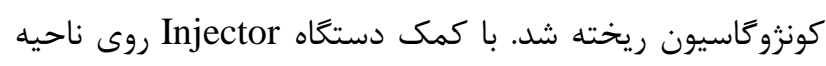

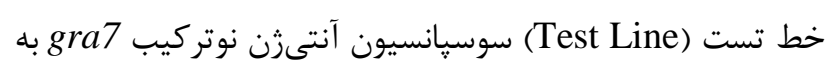

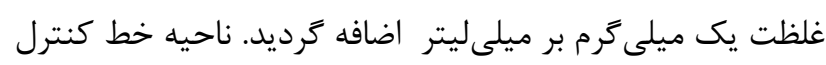

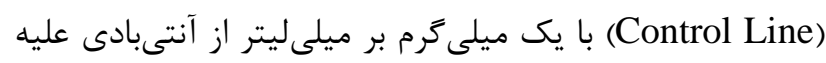

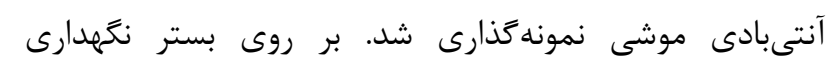
لايههاى مختلف تست شامل لايه نمونه (Backing Plate)

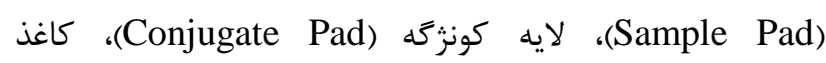

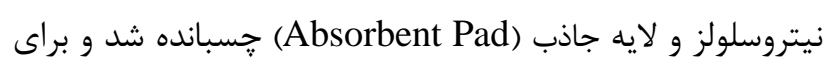

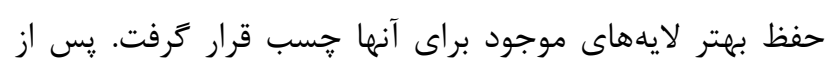

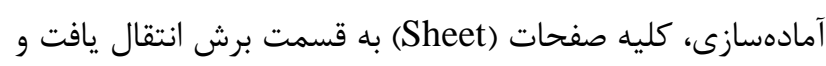

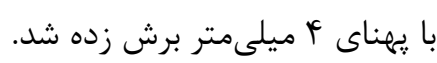

براى بررسى زمان يايدارى كيت از روش تسريع شده استفاده

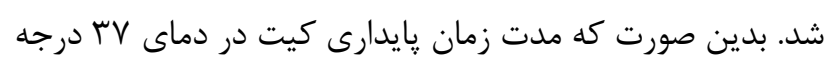

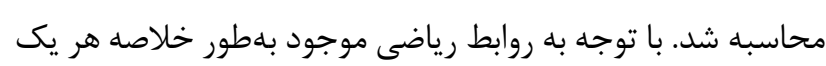

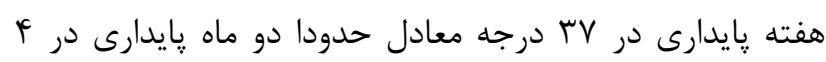
درجه است.

\section{يافته ها}

يس از كشت فرم تاكىزوئيت سويه RH توكسويلاسما در صفاق

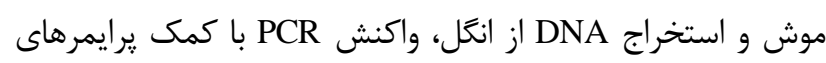

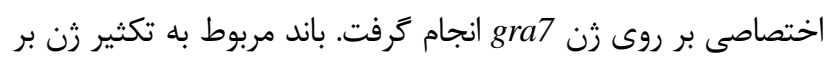

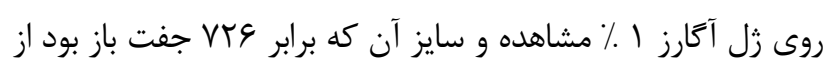

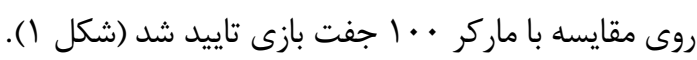
محصول خالصشده PCR و نيز קِلاسميد خالصشده PET-32a

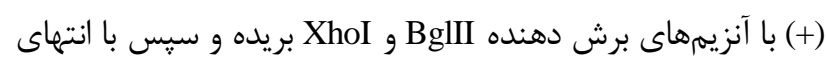

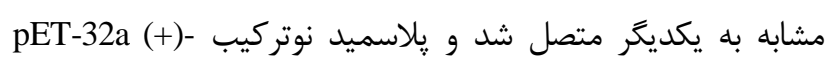

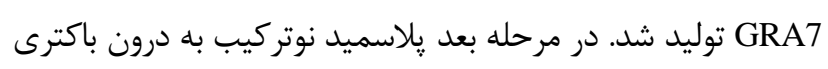

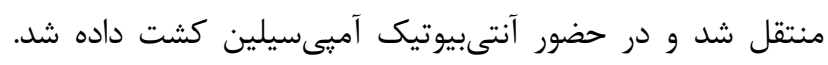

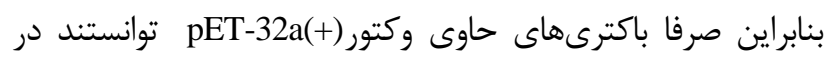

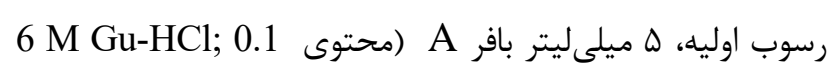
(M NaH2 $\mathrm{PO}_{4}$; 0.01 M Tris-Cl

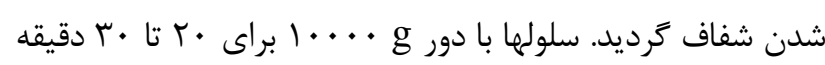

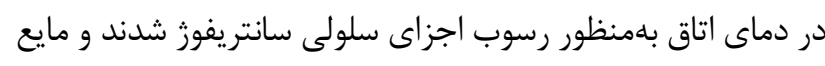

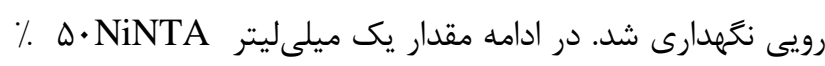

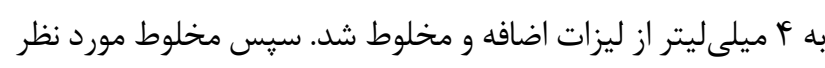

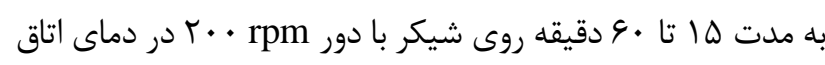

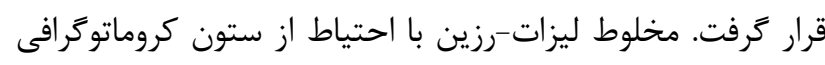
Ni-NTA

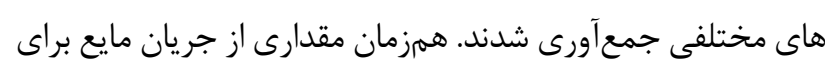

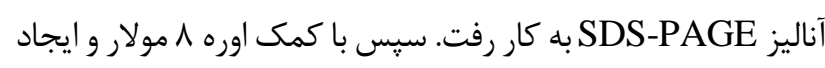
شيب pH يروتئين نوتركيب تخليص شد. يروتئين Trx-gra7

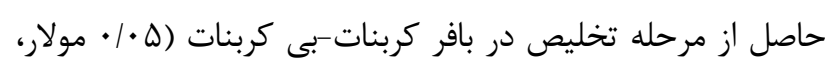

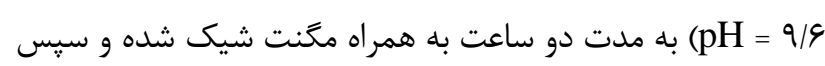

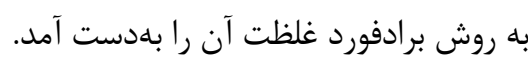

$$
\text { آزمايش بلاتينَ }
$$

در اين مرحله آنتىزن gra7 روى كاغذ نيتروسلولز كوت

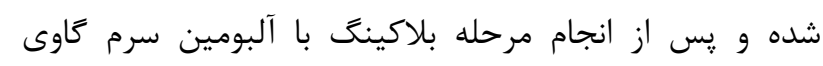

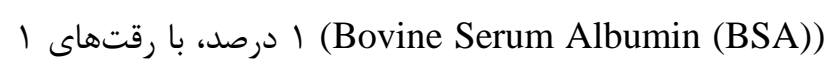

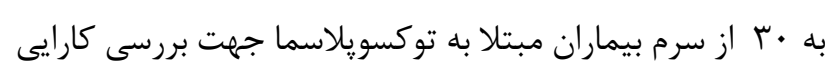

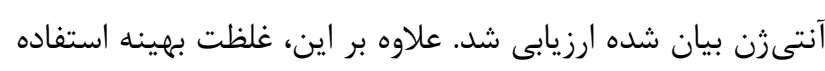

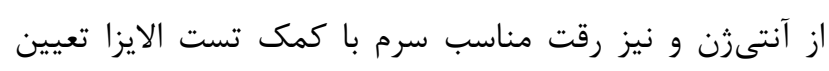

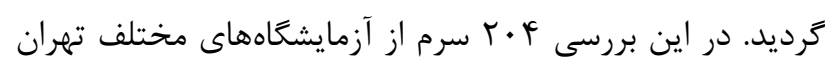

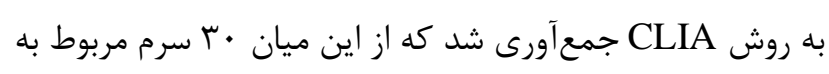

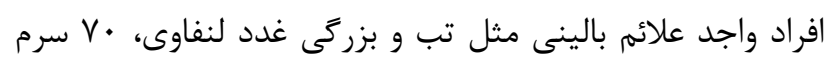

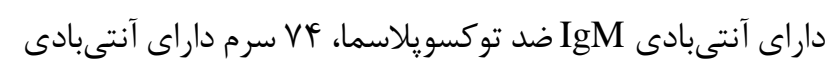
IgG

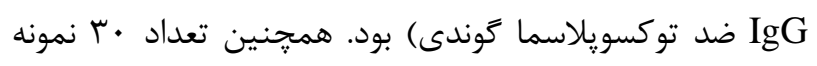

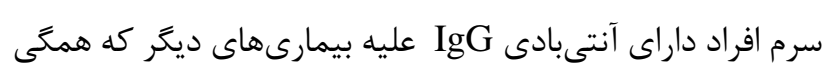

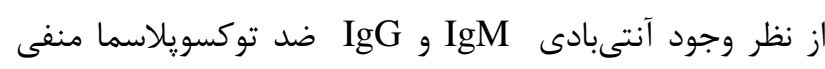

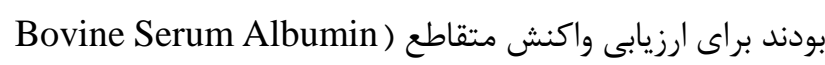
(n=5) مورد بررسى قرار كرفتند. ليشمانيازيس احشائى (BSA)

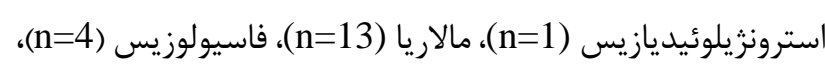

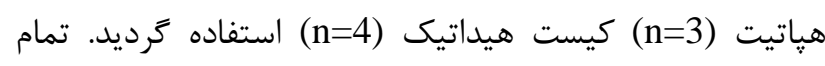

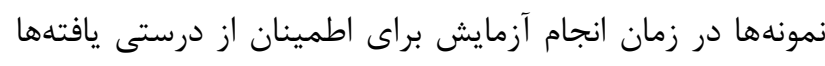

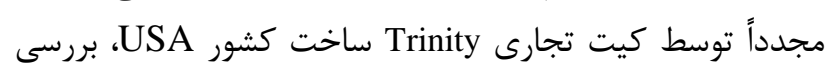

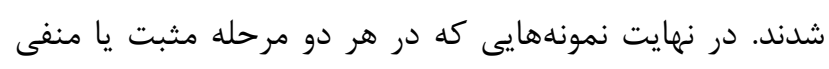
بودند انتخاب شده و در سيستم طراحى شده از آنها استفاده شد. 
Colony PCR و توسط ير ايمرهاى اختصاصى طراحى شده براى تكثير كردن زن تاييد شد (شكل a a b ).
محيط كشت داراى آنتىبيوتيك آميىسيلين رشد كنند. در اين مرحله كلونىهاى نوتركيب اوليه ابتدا با استفاده از روشهاى Quick Check

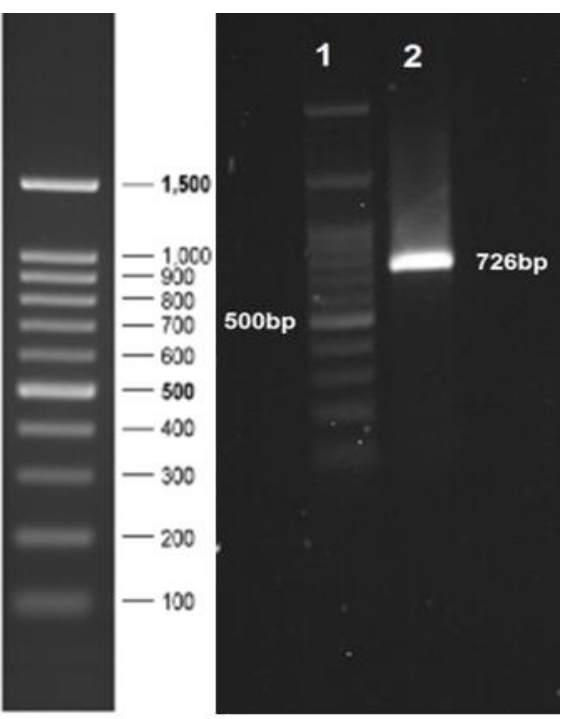

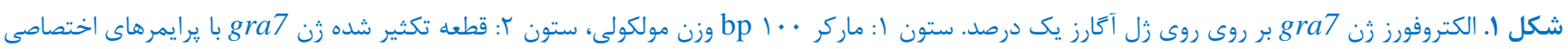

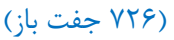

a

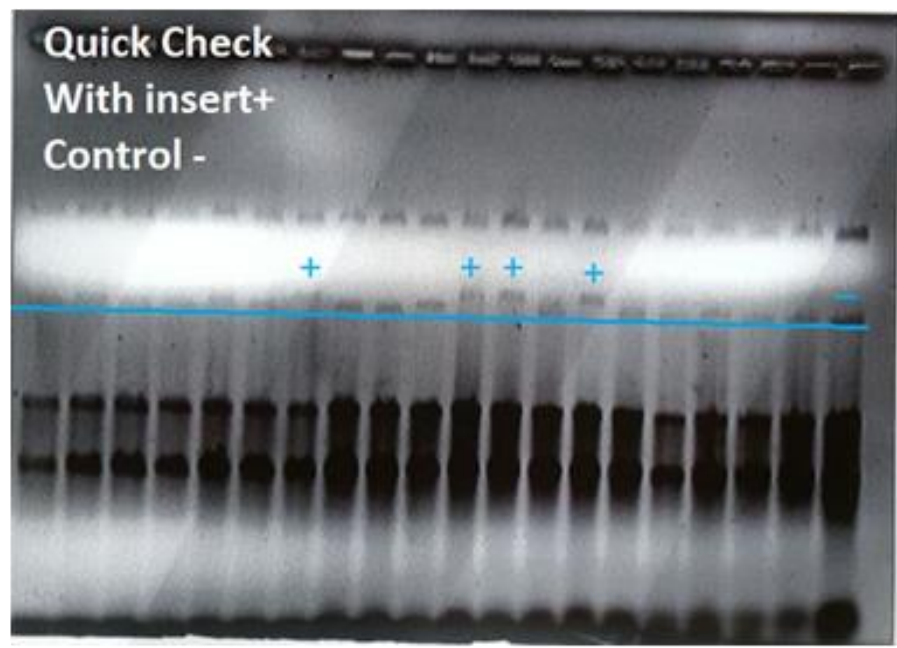

b

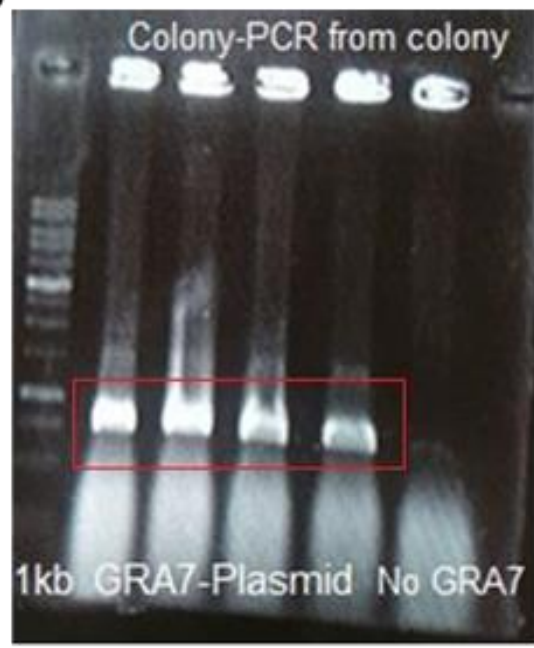

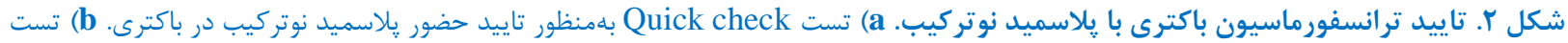
PColony PCR در حضور آنتىبيوتيك.

Macrogen 32a(+) براى تعيين توالى از طريق شركت يِشكام براى شركت

$$
\text { كره جنوبى ارسال گرديد. }
$$

بيان يروتئين در باكترىهاى تحريك شده با IPTG 1.0 mM القاو

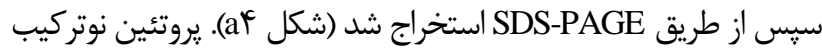

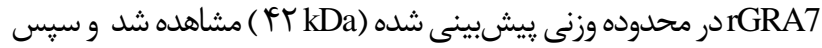

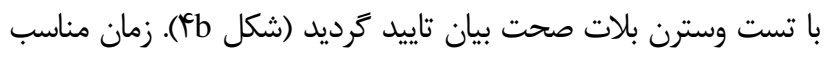

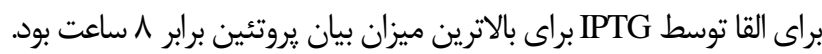

از كلونىهاى تاييدشده، استخراج DNA انجام شد و توسط هضم

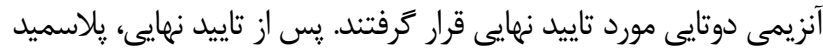

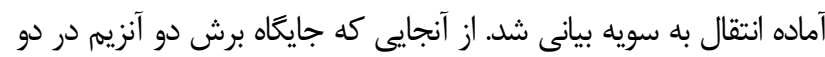
طرف قطعه BgllI,Xhol gra7 است انتظار مىرفت كه طى هضم يلاسميد، قطعه gra7 جدا شود. محصول اين هضم دوآنزيمى باند به طول VY VY جفت

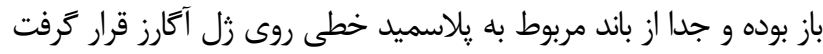

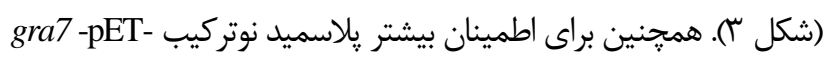


تست دات بلات با سرم انسانى داراى آنتىبادى IgG عليه

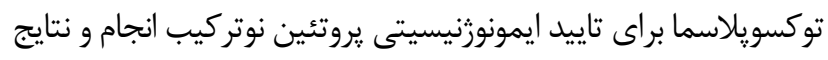

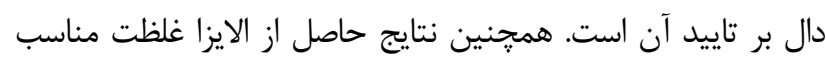

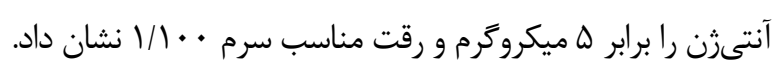

يروتئين نوتركيب فوق با روش كروماتوكر افى تمايلى تخليص شده و بلوسيله SDS-PAGE

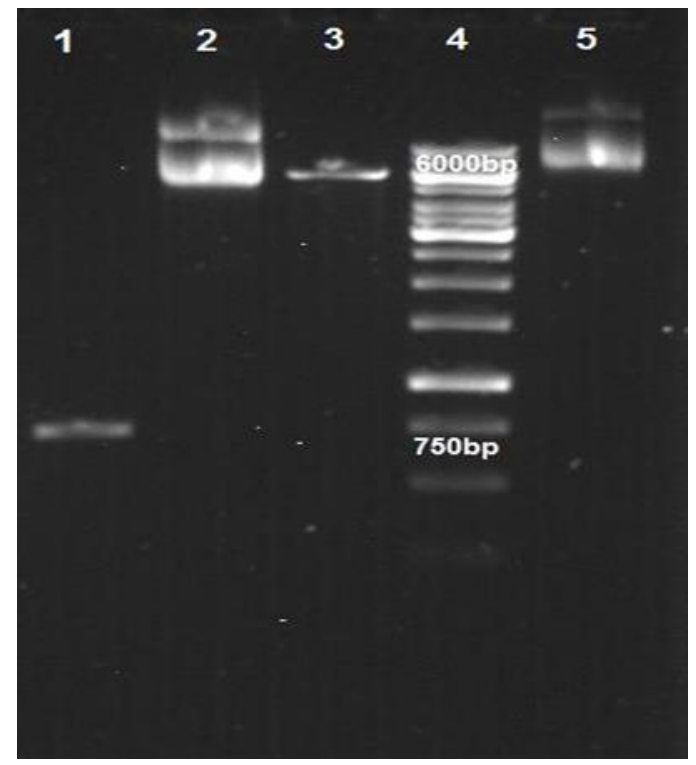

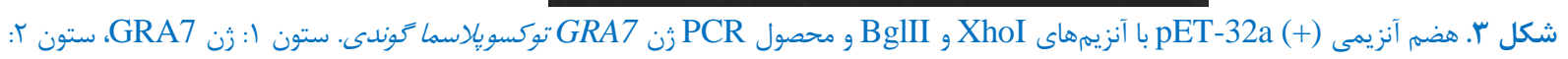

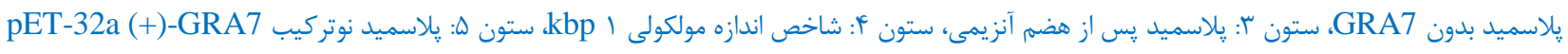

a

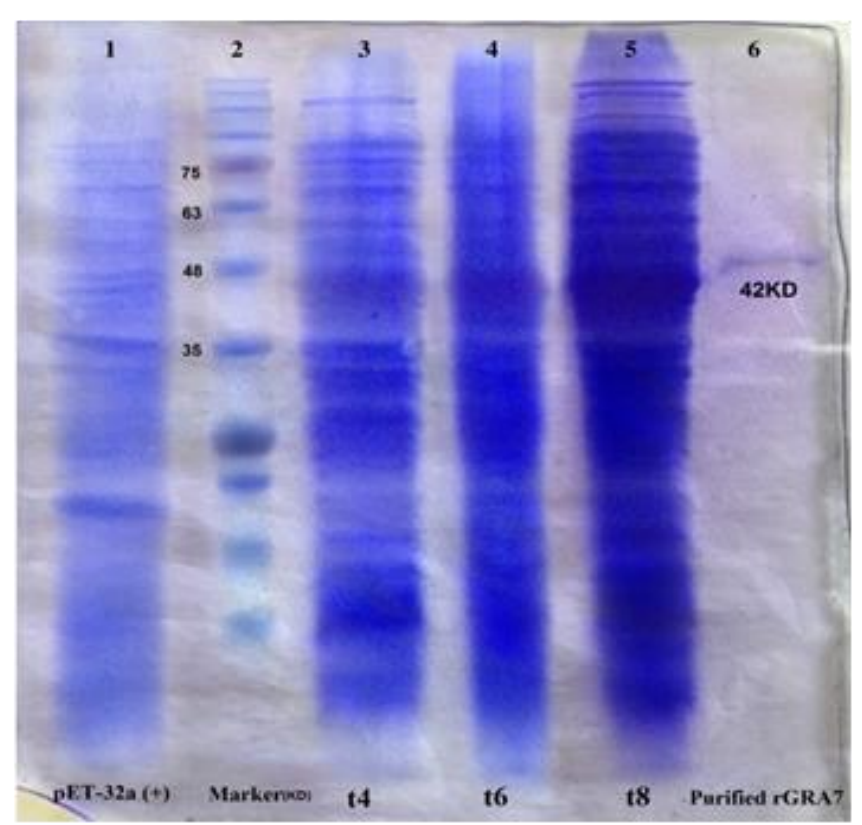

b

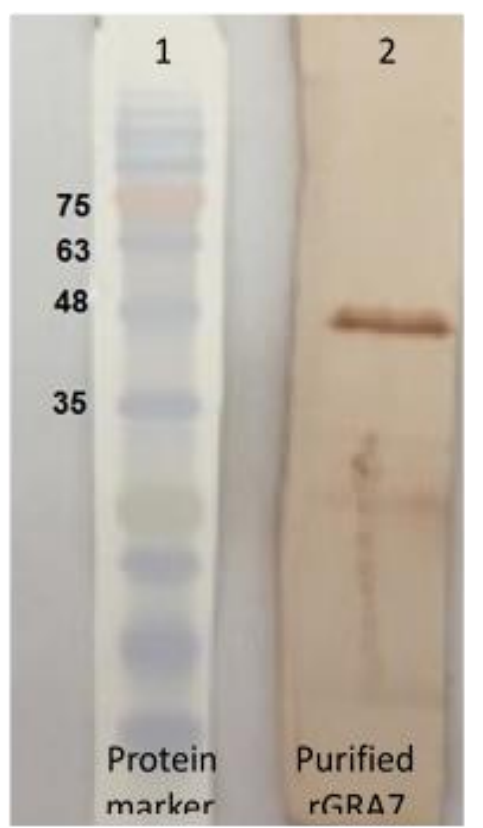

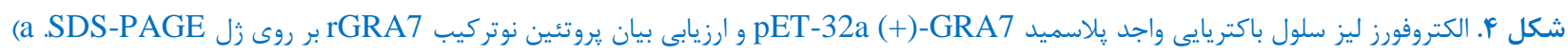

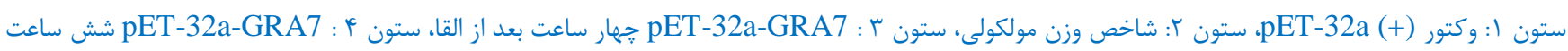

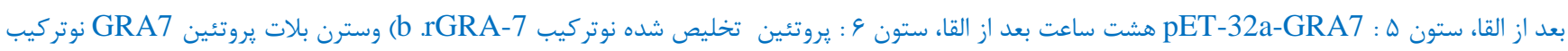

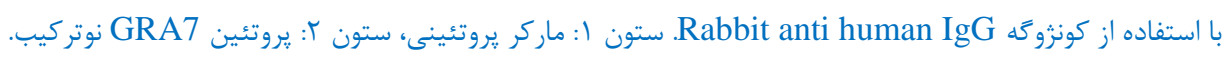


آنتىبادى براى كونزوكه شدن با نانوذارت طلا،

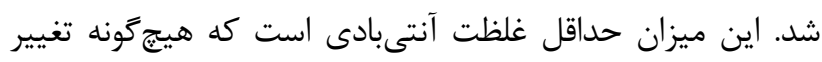

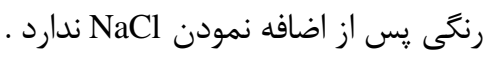

\section{بهينهسازى كونزوكاسيون آنتىبادى ضد انسانى با نانوذارت طلا}

مشاهده دو خط قرمز نشانه تست مثبت و يك خط قرمز نتيجه

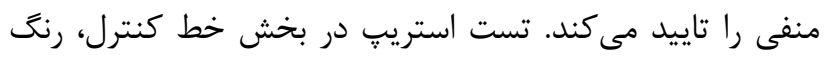

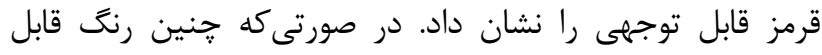

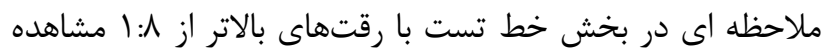

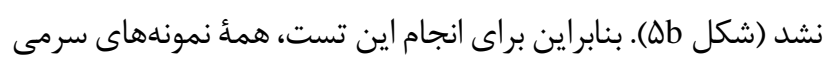

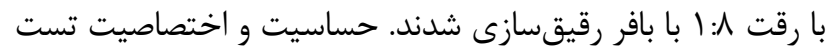

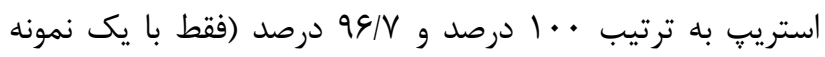
مثبت كاذب) تعيين شد.

a

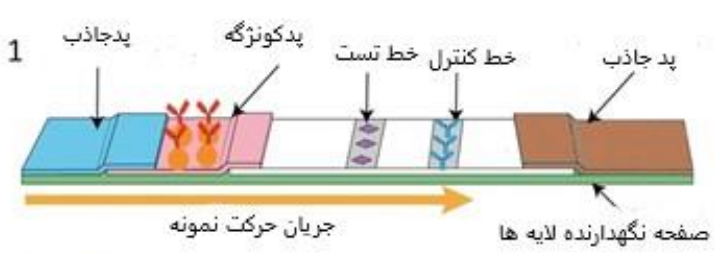

2

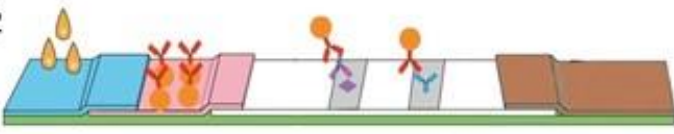

تست نوارى تشخيص آتتى بادى توكسويلاسما

3

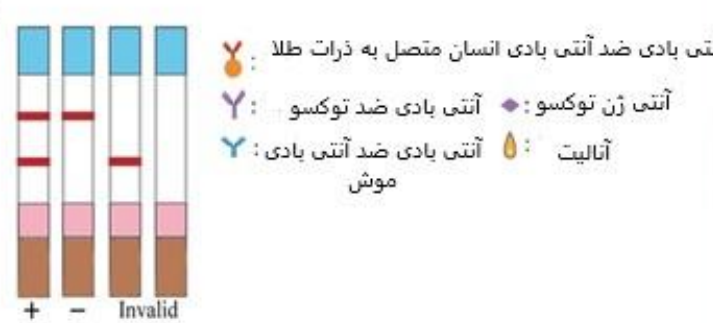

تست استر بِ

براى ساخت كيت نوارى لازم بود كونزگَه توليد شده در لايه

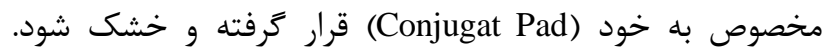
همجنين آنتىزن نوتركيب gra7 در خط تست (test line) و آنتى بادى ضد آنتى بادى موش درخط كنر كنترل نمونه كذارى شد. يس إز انجام اين مرحله از كار براى افزايش طول عمر مواد

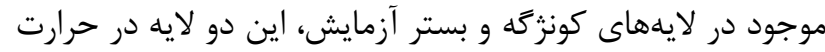

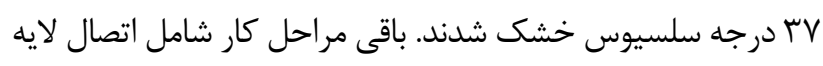

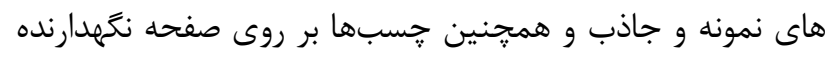
بهصورت دستى انجام كرفت و در نهايت صفحه تست (Sheet) آماده شده و در اندازه دلخواه برش زده شد (شكل (Da). براى متعادل كردن نانوذرات طلا، pH بهينه مورد نياز براى

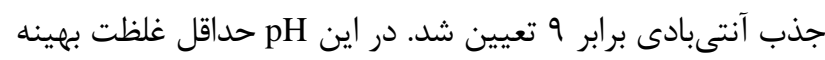

b
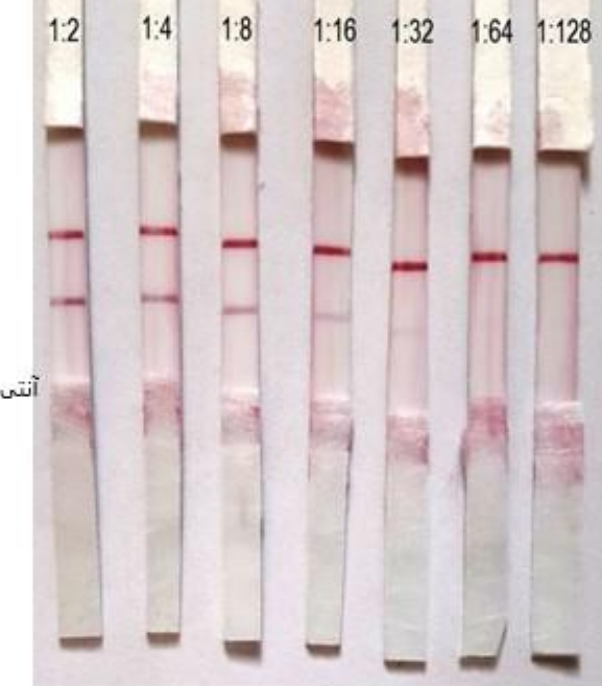

شكل ه. تست استريٍ تشخيص سريع آنتىبادى ضد gra7 توكسويلاسما. a) تصوير شماتيك مراحل آمادهسازى اجزاى تست استريٍ. b) ارزيابى اوليه با كمك

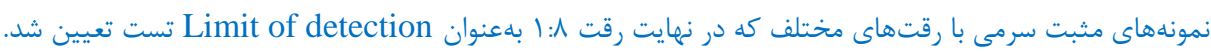

\section{بحث}

تشخيص باموقع و دقيق توكسويلاسموز از جمله مهمترين

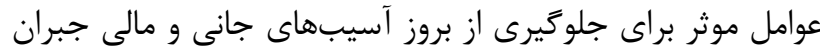

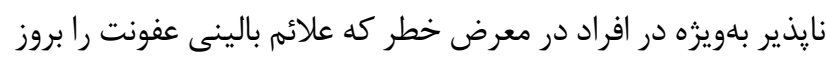

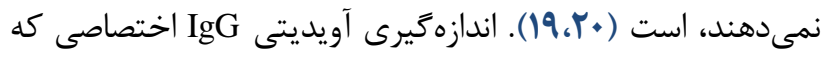

\section{ֶايدارى كيت استريب}

با استفاده از روش تسريع شده مدت زمان بايدارى كيت در

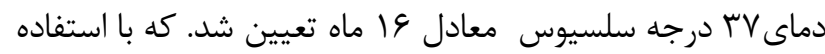

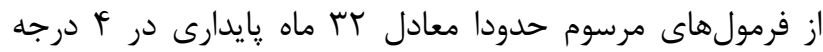
سلسيوس است. 
فرانسوى با همكارى شركت LDBIO در سال VI إ. r، تست استريب

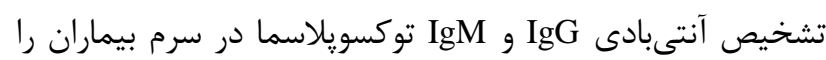

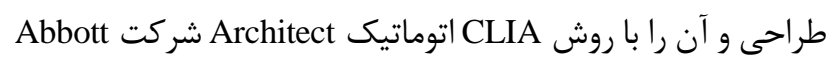

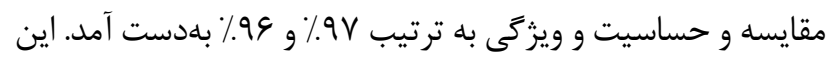

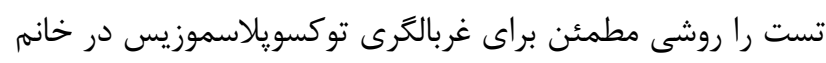

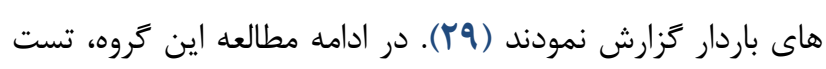

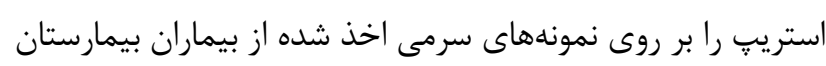

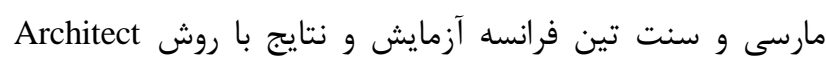

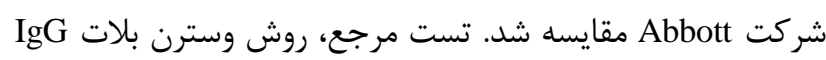

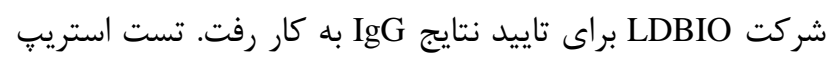

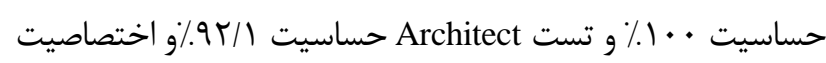

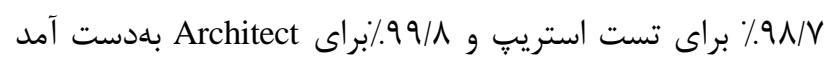

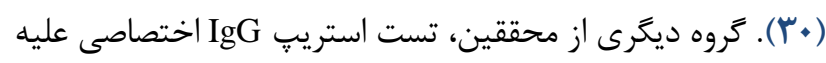

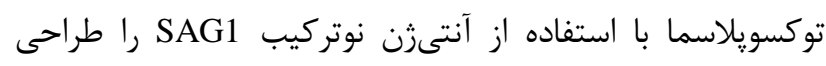

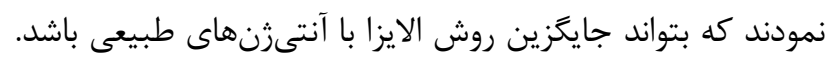

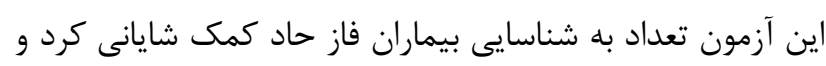

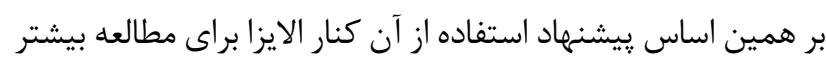

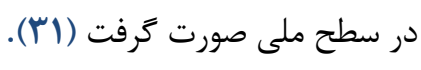

در سال 19 1 ب مطالعه ديكرى انجام شد كه هدف آن، تهيه

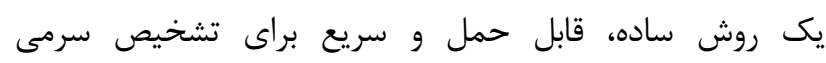

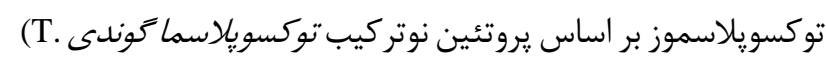

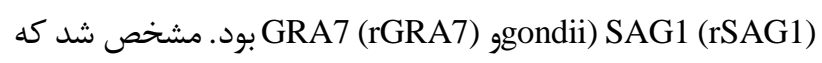
حساسيت و اختصاصيت IgM rGRA7-Dot-ELISA به ترتيب

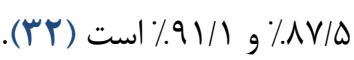

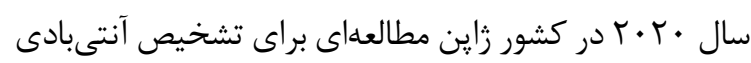

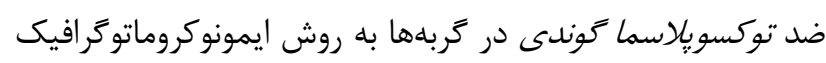

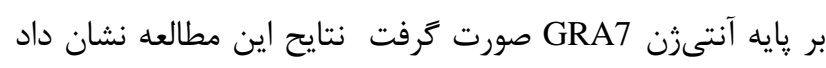

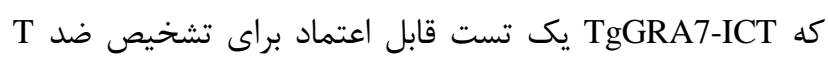

است (سץ).

در راستاى اهميت و ضرورت انجام تستهاى غربالكرى دوران

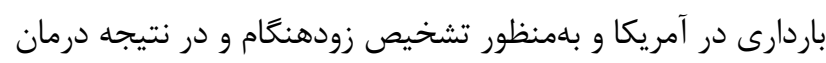

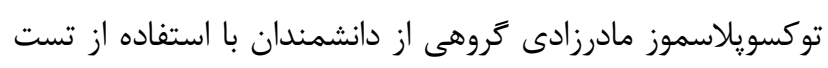

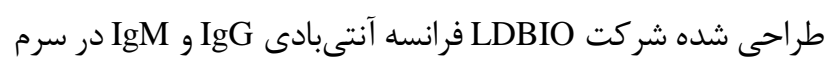

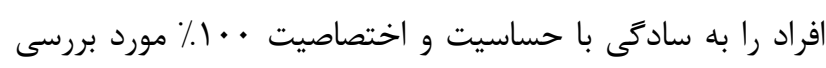

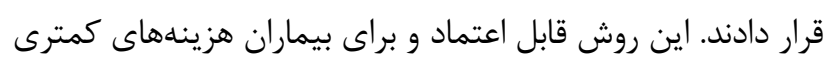

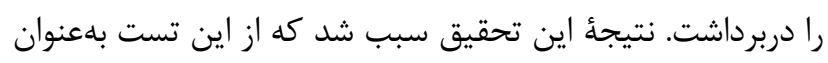

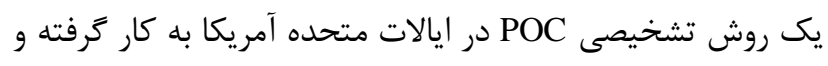

در فاز حاد يايين بوده و با كذر زمان افزايش مىيابد از معمولترين

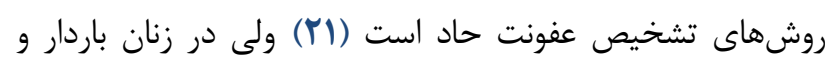

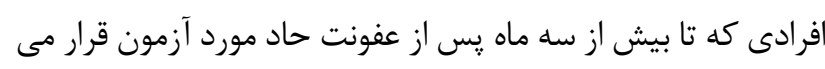

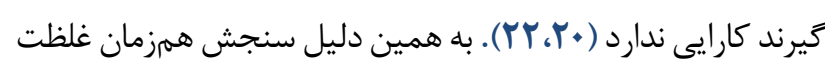

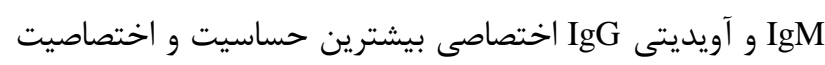

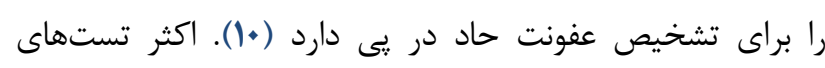

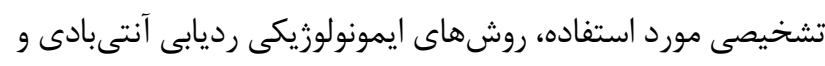

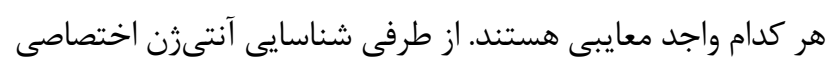
فاز حاد بيمارى مرحله كليدى در طراحى روش هام داى تشخيصى است.

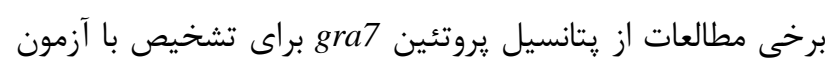

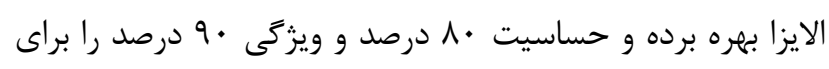

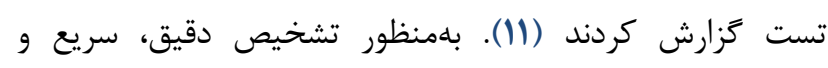

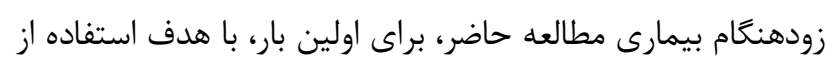

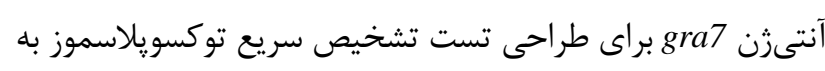

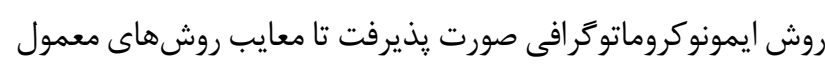
شناسايى را تا حد امكان برطرف سازدو

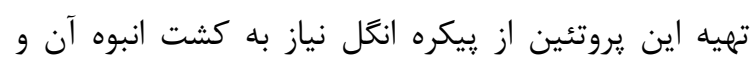

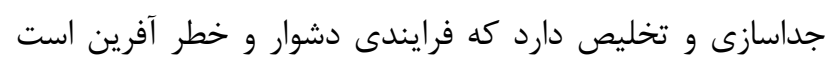

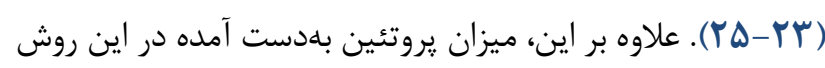

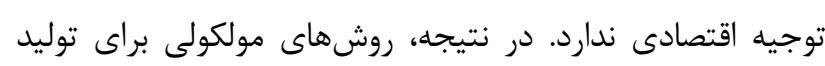
آزمايش gra7

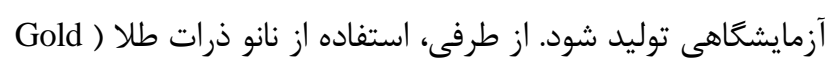
يا طلاى كلوئيدى (Naonoparticle

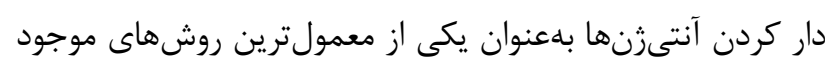

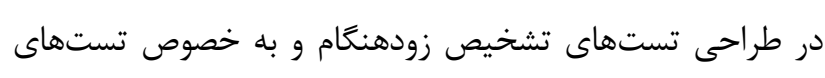

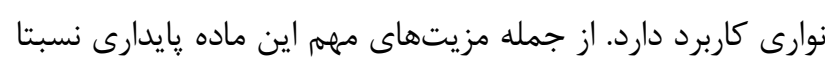

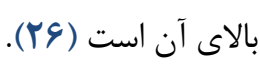
در سال Wang Yh ، و و همكاران، تست استريب تشخيص آنتىرنهاى در كردش خون حيوانات در طى مرحله حاد

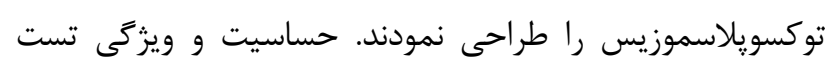

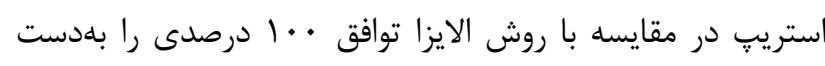

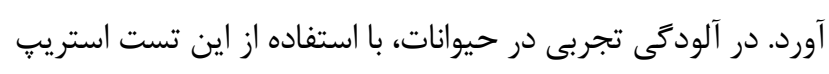

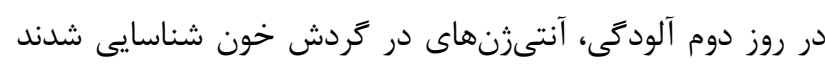

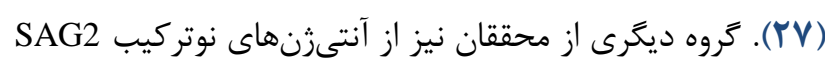

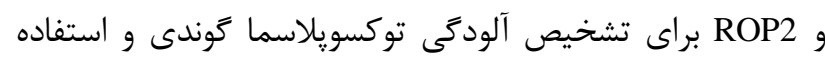

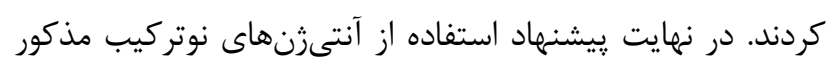

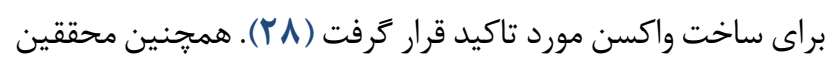




$$
\begin{aligned}
& \text { قبلى منجر به ساخت و ارزيابى موفقيتآميز تست تشخيص سريع } \\
& \text { توكسويلاسموز گرديد. بنابراين نتايج اين تحقيق مىتواند با تامين }
\end{aligned}
$$

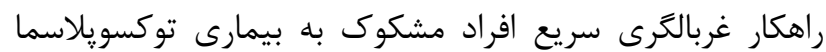

$$
\begin{aligned}
& \text { سبب كاهش زمان تشخيص شده و نيز تفسير نتايج حاصل از تست } \\
& \text { رابراى قشر وسيعى از افراد آسان كند. } \\
& \text { سباسگَزارى }
\end{aligned}
$$

اين اثر توسط دانشگاه علوم يزشكى شهيد بهشتى با شماره

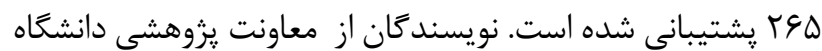
علوم يزشكى شهيد بهشتى تشكر مى كنند.

$$
\text { تعارض در منافع }
$$

$$
\text { اين مقاله يروهشى مستقل است كه بدون حمايت مالى }
$$$$
\text { سازمانى انجام شده است. در انجام مطالعهُ حاضر، نويسندكان }
$$$$
\text { هيجزَّونه تضاد منافعى نداشتهاند. }
$$

\section{Referance}

1. Dubey JP. The history of Toxoplasma gondii-the first 100 years. J Eukaryot Microbiol 2008;55(6):467-75. [DOI:10.1111/j.1550-7408.2008.00345.x] [PMID]

2. Wolf A, Cowen D, Paige B. Human toxoplasmosis: occurrence in infants as an encephalomyelitis verification by transmission to animals. Science (Washington). 1939;89(2306). [DOI:10.1126/science.89.2306.226] [PMID]

3. Mamidi A, DeSimone JA, Pomerantz RJ. Central nervous system infections in individuals with HIV-1 infection. J Neurovirol. 2002;8(3):158-67. [DOI:10.1080/13550280290049723] [PMID]

4. Gross U, Holpert M, Goebel S. Impact of stage differentiation on diagnosis of toxoplasmosis. Ann Ist Super Sanita. 2004;40(1):65-70.

5. Prince HE, Wilson M. Simplified assay for measuring Toxoplasma gondii immunoglobulin $\mathrm{G}$ avidity. Clin Diagn Lab Immunol. 2001;8(5):904-8. [DOI:10.1128/CDLI.8.5.904-908.2001] [PMID] [PMCID]

6. Pfrepper K-I, Enders G, Gohl M, Krczal D, Hlobil H, Wassenberg D, et al. Seroreactivity to and avidity for recombinant antigens in toxoplasmosis. Clin Diagn Lab Immunol.

2005;12(8):977-82.

[DOI:10.1128/CDLI.12.8.977-982.2005]

[PMID]

[PMCID]

7. Roberts A, Hedman K, Luyasu V, Zufferey J, Bessières M-H, Blatz R-M, et al. Multicenter evaluation of strategies for serodiagnosis of primary infection with Toxoplasma gondii. Clin Microbiol Infect. 2001;20(7):467-74. [DOI:10.1007/PL00011289] [PMID]

$$
\begin{aligned}
& \text { باعث يِيخيرى از سقط جنين، هزينههاى گزاف ناشى از عقب } \\
& \text { ماندگى هاى ذهنى و اجتماعى شود (MF). } \\
& \text { در اين تحقيق براى اولين بار تست استري״ با استفاده از } \\
& \text { آنتىزن نوتركيب gra7 براى تشخيص توكسويلاسما طراحى شد. } \\
& \text { اين تست بسيار ساده و سريع عملكردى با اختصاصيت بالا نشان داد }
\end{aligned}
$$

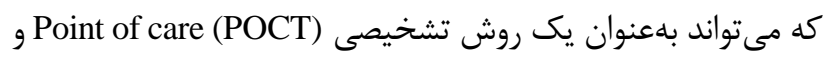

$$
\begin{aligned}
& \text { نيز در ارزيابىهاى در سطح وسيع بالينى كاربرد زيادى داشته باشد. }
\end{aligned}
$$

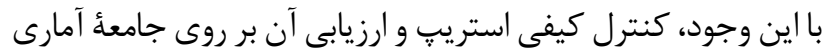

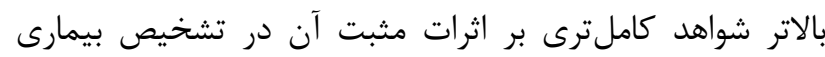

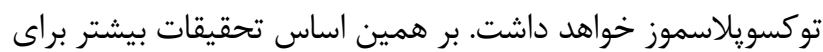

$$
\begin{aligned}
& \text { ارتقا و بهينهسازى مطالعه حاضر توصيه مىشود. } \\
& \text { نتيجهليرى }
\end{aligned}
$$

در اين مطالعه انتخاب آنتىزن مناسب براساس شاخصههاى

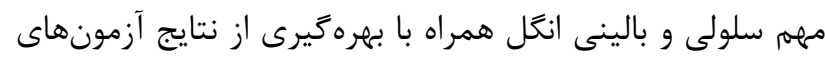

8. Abdizadeh R, Maraghi S, Ghadiri AA, Tavalla M, Shojaee S. Cloning and Expression of Major Surface Antigen 1 Gene of Toxoplasma gondii RH Strain Using the Expression Vector pVAX1 in Chinese Hamster Ovary Cells. Jundishapur J Microbiol. 2015;8(3):e22570. [DOI:10.5812/jim.22570]

9. Grzybowski MM, Dziadek B, Dziadek J, Gatkowska J, Dzitko K, Dlugonska H. Toxoplasma gondii: cloning, expression and immunoreactivity of recombinant ROP5 and ROP18 antigens. Exp. Parasitol. 2015;150:1-6. [DOI:10.1016/j.exppara.2015.01.006] [PMID]

10. Kotresha D, Noordin R. Recombinant proteins in the diagnosis of toxoplasmosis. Apmis. 2010;118(8):529-42. [DOI:10.1111/j.1600-0463.2010.02629.x] [PMID]

11. Araújo PRB, Ferreira AW. High diagnostic efficiency of IgM-ELISA with the use of multiple antigen peptides (MAP1) from T. gondii ESA (SAG-1, GRA-1 and GRA7 ), in acute toxoplasmosis. Rev Inst Med Trop Sao Paulo. 2010;52(2):63-8. [DOI:10.1590/S003646652010000200001] [PMID]

12. Dunn JD, Ravindran S, Kim S-K, Boothroyd JC. The Toxoplasma gondii dense granule protein GRA7 is phosphorylated upon invasion and forms an unexpected association with the rhoptry proteins ROP2 and ROP4. Infect Immun. 2008;76(12):5853-61. [DOI:10.1128/IAI.01667-07] [PMID] [PMCID]

13. Igarashi M, Kano F, Tamekuni K, Kawasaki P, Navarro I, Vidotto O, et al. Toxoplasma gondii: cloning, sequencing, expression, and antigenic characterization of ROP2, GRA5 and GRA7. Genet Mol Res. 2008:305-13. [DOI:10.4238/vol7-2gmr423] [PMID]

14. Sun X, Wang Z, Li J, Wei F, Liu Q. Evaluation of an indirect ELISA using recombinant granule antigen GRA1, 
GRA7 and soluble antigens for serodiagnosis of Toxoplasma gondii infection in chickens. Res Vet Sci. 2015;100:161-4. [DOI:10.1016/j.rvsc.2015.04.011] [PMID]

15. Wang Z, Ge W, Huang S-Y, Li J, Zhu X-Q, Liu Q. Evaluation of recombinant granule antigens GRA1 and GRA7 for serodiagnosis of Toxoplasma gondii infection in dogs. BMC Vet Res. 2014;10(1):158. [DOI:10.1186/1746-6148-10-158] [PMID] [PMCID]

16. Wang Z, Ge W, Li J, Song M, Sun H, Wei F, et al. Production and evaluation of recombinant granule antigen protein GRA7 for serodiagnosis of Toxoplasma gondii infection in cattle. Foodborne Pathog Dis. 2014;11(9):734-9. [DOI:10.1089/fpd.2014.1749] [PMID]

17. Gopal GJ, Kumar A. Strategies for the production of recombinant protein in Escherichia coli. Protein $\mathbf{J}$. 2013;32(6):419-25. [DOI:10.1007/s10930-013-9502-5] [PMID]

18. Wang Y, Wang L, Zhang J, Wang G, Chen W, Chen L, et al. Preparation of colloidal gold immunochromatographic strip for detection of Paragonimiasis skrjabini. PloS one. 2014;9(3):e92034. [DOI:10.1371/journal.pone.0092034] [PMID] [PMCID]

19. Ferreira MS, Borges AS. Some aspects of protozoan infections in immunocompromised patients- a review. Mem Inst Oswaldo Cruz. 2002;97(4):443-57. [DOI:10.1590/S0074-02762002000400001] [PMID]

20. Wallon M, Peyron F. Congenital Toxoplasmosis: A Plea for a Neglected Disease. PLoS Pathog. 2018;7(1):25. [DOI:10.3390/pathogens7010025] [PMID] [PMCID]

21. Beghetto E, Buffolano W, Spadoni A, Del Pezzo M, Di Cristina M, Minenkova $\mathrm{O}$, et al. Use of an immunoglobulin $\mathrm{G}$ avidity assay based on recombinant antigens for diagnosis of primary Toxoplasma gondii infection during pregnancy. Clin Microbiol Rev. 2003;41(12):5414-8. [DOI:10.1128/JCM.41.12.54145418.2003] [PMID] [PMCID]

22. Dubey J, Jones J. Toxoplasma gondii infection in humans and animals in the United States. Int J Parasitol Parasites Wildl. 2008;38(11):1257-78. [DOI:10.1016/j.ijpara.2008.03.007] [PMID]

23. Hiszczyńska-Sawicka Eb, Brillowska-Dąbrowska A, Dąbrowski S, Pietkiewicz H, Myjak P, Kur J. High yield expression and single-step purification of Toxoplasma gondii SAG1, GRA1, and GRA7 antigens in Escherichia coli. Protein Expr Purif. 2003;27(1):150-7. [DOI:10.1016/S1046-5928(02)00593-4]

24. Babaie J, Miri M, Sadeghiani G, Zare M, Khalili G, Golkar M. Expression and Single-step Purification of GRA8 Antigen of Toxoplasma gondii in Escherichia coli. Avicenna J Med Biotechnol. 2011;3(2):67-77.

25. Walls D, Loughran ST. Tagging recombinant proteins to enhance solubility and aid purification. Methods Mol Biol (Clifton, NJ). 2011;681:151-75. [DOI:10.1007/978-160761-913-0_9] [PMID]

26. Wong RC, Tse HY. Lateral flow immunoassay. New York: Springer; 2009. [DOI:10.1007/978-1-59745-240-3]

27. Wang Y-H, Li X-R, Wang G-X, Yin H, Cai X-P, Fu B-Q, et al. Development of an immunochromatographic strip for the rapid detection of Toxoplasma gondii circulating antigens. Parasitol Int. 2011;60(1):105-7. [DOI:10.1016/j.parint.2010.11.002] [PMID]

28. Yan H, Yan H, Tao Y, Chen H, Li G, Gong W, et al. Application and expression of Toxoplasma gondii surface antigen 2 (SAG2) and rhoptry protein 2 (ROP2) from recombinant Escherichia coli strain. Trans R Soc Trop Med Hyg. 2012;106(6):356-62. [DOI:10.1016/j.trstmh.2012.02.008] [PMID]

29. Chapey E, Wallon M, Peyron F. Evaluation of the LDBIO point of care test for the combined detection of toxoplasmic IgG and IgM. Clin Chim Acta. 2017;464:200-1. [DOI:10.1016/j.cca.2016.10.023] [PMID]

30. Mahinc C, Flori P, Delaunay E, Guillerme C, Charaoui S, Raberin H, et al. Evaluation of a new ICT test (LDBIO Diagnostics) to detect toxoplasma IgG and IgM: comparison with the routine Architect technique. J Clin Microbiol. 2017:JCM. 01106-17. [DOI:10.1128/JCM.01106-17] [PMID] [PMCID]

31. Kim YH, hoo Lee J, kyu Ahn S, Kim T-S, Hong S-J, Chong C-K, et al. Seroprevalence of Toxoplasmosis with ELISA and Rapid Diagnostic Test among Residents in Gyodong-do, Inchon city, Korea: A Four-Year Follow-up. Korean J Parasitol. 2017;55(3):247. [DOI:10.3347/kjp.2017.55.3.247] [PMID] [PMCID]

32. Teimouri A, Modarressi MH, Shojaee S, Mohebali M, Rezaian M, Keshavarz H. Development, optimization, and validation of an in-house Dot-ELISA rapid test based on SAG1 and GRA7 proteins for serological detection of Toxoplasma gondii infections. J Glob Antimicrob Resist. 2019; 12:2657. [DOI:10.2147/IDR.S219281] [PMID] [PMCID]

33. YBAÑEZ RH, KYAN H, NISHIKAWA Y. Detection of antibodies against Toxoplasma gondii in cats using an immunochromatographic test based on GRA7 antigen. J Vet Med Sci. 2020:19-0654. [DOI:10.1292/jvms.190654] [PMID]

34. Begeman IJ, Lykins J, Zhou Y, Lai BS, Levigne P, El Bissati $\mathrm{K}$, et al. Point-of-care testing for Toxoplasma gondii IgG/IgM using Toxoplasma ICT IgG-IgM test with sera from the United States and implications for developing countries. PLoS Negl Trop Dis. 2017;11(6):e0005670.

[DOI:10.1371/journal.pntd.0005670] [PMID] [PMCID] 